\title{
Transition out of Marriage and its Effects on Health and Health-Related Quality of Life among Females and Males. COURAGE and COURAGE-POLFUS-Population Based Follow-Up Study in Poland
}

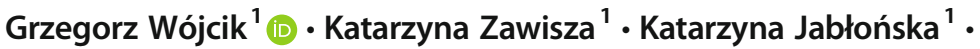 \\ Tomasz Grodzicki $^{2}$ - Beata Tobiasz-Adamczyk ${ }^{1}$
}

Received: 11 May 2018 / Accepted: 7 June 2019/ Published online: 9 July 2019

(C) The Author(s) 2019

\begin{abstract}
The study explores short-term effects of dissolution of union through divorce/ separation and widowhood on physical and mental health as well as healthrelated quality of life (HRQoL) among females and males in Poland. Considering social selection and social causation theories, the study poses following research questions: are there differences in physical and mental health as well as health-related quality of life that are caused by a marital transition compared to remaining married/cohabiting? Do marital status transitions have different effects concerning physical and mental health and health-related quality of life among females and males? Data for the analysis were available for 1073 people (18+) who participate in the COURAGE-Poland populationbased study from 2011 (baseline) and 2015-2016 COURAGE-POLFUS (follow-up). Health status was measured by the WHODAS II and the presence of depression based on the Composite International Diagnostic Interview. Healthrelated quality of life was assessed by WHOQOL-AGE scale. The analysis has been conducted using the analysis of variance, multinomial logistic regression and generalized liner mixed model according to the dependent variable. Results do suggest that transition out of marriage weakens mental health although the differences in physical health seemed to not be significant compared to the continuously married/cohabiting. The marital dissolution especially causes a decline in the mental health as well as health-related
\end{abstract}

Electronic supplementary material The online version of this article (https://doi.org/10.1007/s11482-01909742-z) contains supplementary material, which is available to authorized users.

Grzegorz Wójcik

grzegorz.wojcik@uj.edu.pl

Extended author information available on the last page of the article 
quality of life of males who transitioned to a widowed life. There has not been observed statistically significant change in terms of healthrelated quality of life between first and second wave of the survey among both widowed and divorced males and females.

Keywords Transition out of marriage $\cdot$ Physical health $\cdot$ Mental health $\cdot$ Health-related quality of life $\cdot$ Gender differences

\section{Introduction}

In the last few decades, the family structure in Western European countries has experienced many changes. Sociologists have pointed out, among others, the increase of cohabitation (Kasearu and Kutsar 2011; Perelli-Harris et al. 2014), delayed marriages and the rise of non-marital childbearing, as well as the increase of divorce rates (Amato 2010; Schoen et al. 2007). The same patterns have occurred recently in Poland as according to the Central Statistical Office, approximately 30\% of Polish marriages established currently lead to divorce (Demographic Yearbook of Poland 2017). Additionally, Polish sociologists indicate that informal relationships are becoming more and more popular especially among young people who do not have previous marital experiences (Szukalski 2013).

The phenomena concerning the family structure mentioned have a strong influence on individuals' health as a family provides economic, social and psychological resources (Carr and Springer 2010). According to numerous studies, married individuals are shown to have lower rates of chronic illness, physical limitations and mortality, and, in general, better health than nonmarried people (Pienta et al. 2000; Rogers 1995; Williams and Umberson 2004; Williams et al. 2010). Those continuously married also appear to have better mental health than their unmarried counterparts (Lamb et al. 2003; Soons and Kalmijn 2009; Wade and Pevalin 2004; Zella 2017). Marriage as well as cohabitation convey protective health benefits by increasing the availability of social support, stability of life and mutual monitoring of health behaviours (Zella 2017). Being in an intimate relationship is also responsible for a better quality of life (Naess et al. 2015) because marriage and cohabitation may bring satisfaction in sexual activity, companionship and sharing household resources (Lucas 2008), support and mutual caring, as well as economic benefits (Argyle 1999).

Nevertheless, the costs to the mental health of exiting marriage through divorce or widowhood seem to be substantially stronger compared to the mental health benefits of marriage entry (Musick and Bumpass 2010; Wu and Hart 2002). The evidence of this thesis are numerous longitudinal studies (Kim and McKenry 2002 ; Lee and DeMaris 2007; Simon 2002; Strohschein et al. 2005; Wade and Pevalin 2004; Wilcox et al. 2003; Williams 2003; Wu and Hart 2002) which show that divorces and widowhood are associated with the substantial decline in mental health. Scholars indicate, among others, the decline of mental health, the growth of depression, anxiety and also alcohol abuse (Chen et al. 1999; Horwitz et al. 1996; Kim and McKenry 2002; Simon 2002). 


\section{Theoretical Background of Current Research}

There are two main approaches explaining relationships between marital status transition and health. Firstly, the social causation theory which suggests that there are aspects of being married/cohabitant that make it advantageous to health in comparison with single life (Williams and Umberson 2004). The social causation model argues that marital partnerships protect people in ways that are beneficial to psychological health and occupying the role of a widowed or divorced person increases the likelihood of mental health problems because of the strains that accompany a marital disruption (Umberson et al. 2009). The other causation argument claims that partnership transitions affect people's health which can be short-lived or may persist. However, after a temporary decline in health following a transition out of marriage, the health of the divorced or widowed person should be no different from that of a married person. Using three waves of data from the United States collected between 1980 and 1988, Booth and Amato claimed (1991) the level of psychological distress increases just prior to marital dissolution, remains elevated up to 2 years and finally returns to the level reported by those who are continually married. Similarly, Hope et al. (1999) found elevated levels of psychological distress only relatively shortly after a marital dissolution. Using the same data as Booth and Amato (1991), but with a fourth wave added, Johnson and $\mathrm{Wu}$ (2002) reported on the other hand that the effect of divorce on psychological distress does not appear to diminish over the years following divorce.

The second perspective - the social selection theory - informs us that healthy people are selected into marriage/cohabitation as desirable partners, whereas the unhealthy remain single (Wu et al. 2012). In other words, people in poor health are less likely to marry and are more likely to divorce than people in good health. This paradigm also means that people that have some psychological traits such as extraversion, optimism and emotional stability are characterized by a higher rate of life satisfaction than those who are unattached (Naess et al. 2015). The social selection perspective would also argue that the formerly married exhibit poorer health than married people and are consequently more likely to experience dissolution and less likely to make a transition into remarriage (Marks and Lambert 1996). Blekesaune (2008) showed that poor mental health precedes marital dissolution and Mastekaasa (1994) also found evidence that poor psychological well-being forebode marital dissolution over a 2- to 4-year period. Additionally, Gardner and Oswald (2006) found that mental distress can predict marital disruption 1 and 2 years later in 11 waves of the British Household Panel Survey (BHPS) whereas Wade and Pevalin (2004) using the same tool supported the social selection model, but only in a group of divorced/separated, yet not among the widowed. They claimed that mental health problems among the divorced measured 4 years previously are predictive of marital disruption. In the context of cohabitation, Pevalin and Ermisch (2004) found that high levels of mental distress increased the probability of exiting cohabitations.

Divorce, separation or widowhood are treated as stressful life events because these situations require an adjustment to a new way of living from an individual (Dupre and Meadows 2007; Ensel et al. 1996; Zisook and Shuchter 1991). According to Pearlin (1989), there are two major types of social stressors: life events and chronic strains. Firstly, the stress of life events is associated with life events originating in negative situations and refers to changes that are undesired, unscheduled, non-normative and 
most harmful, such as widowhood. According to the Social Readjustment Rating Scale developed by Holmes and Rahe (1967) which measures the presumed relationship between stress and particular life experiences, the death of a spouse is ranked the highest with a relative stress value of 100 and divorce is second with a value of 73. Secondly, there are chronic strains including persistent problems, conflicts and threats that many people face in their daily lives (e.g., economic hardship, single parenting, social isolation) that lead to persistent psychological distress. These kinds of strains may develop insidiously and may persist until people readjust to the new expectations and norms. However, as Pearlin (1989) states, these two kinds of stressors often flow together in people's experiences. In this perspective, divorce/separation and widowhood could be considered as life events stressors, but also strains can precipitate transitions out of marriage regarded as stressful events. These findings are interrelated with the shock theory that claims that after widowhood and divorce a temporary decline of hardiness occurs, which is the result of the lack of benefits coming from having a life partner. As a consequence, the necessity of redefining social roles considered to be a very stressful experience emerges (Birch 1997).

The other useful explanation for stress phenomena connected with the transition out of marriage is provided by the socio-emotional selectivity theory developed by Carstensen (Carstensen 1992). According to this paradigm, although there are reductions in social contacts with acquaintances across the life span, interactions in significant relationships increase. In other words, over the adult life course interactions with social partners from whom an individual derives affective gains are more frequent, whereas relations providing fewer emotional rewards and being less satisfying become less frequent. In the context of intimate unions, this theory suggests that marriage is becoming more important to older people as they begin to narrow down their social networks. As a consequence, if the marital relationship becomes more salient to individuals at later ages, exiting from it undermines health more strongly compared to younger adults.

The final important approach concerning marital status change and health is the social role theory (Ross 1995). According to this paradigm, the greater psychological distress reported by the divorced person is the result of the more difficult life circumstances they experience. Living as a divorced individual often involves social isolation, lack of social support, economic hardship and added childcare responsibilities for those who are parents. The greater distress levels of divorced people considered as a permanent feature of that state could be reduced by entering into remarriage or cohabitation (Ross 1995).

\section{Previous Research Concerning Relationship between Transition out of Marriage, Health and Gender}

In the context of physical health in relation to gender, research indicates that marital dissolution undermines men's health, but not women's (Williams and Umberson 2004; $\mathrm{Wu}$ and Hart 2002). The negative health behaviour observed by scientists after marital break-up includes the increased risk of alcohol consumption among men (Wu and Hart 2002), as well as tobacco use (Umberson 1992), whereas smoking (Rydzewski 2010) and loss of weight have been noticed among women (Umberson 1992). 
The mental health effects of marital break-up, either due to divorce or widowhood mostly encompass the occurrence of anxiety and depression among both females and males. However, the results of studies whether men or women suffer more after divorce/separation are inconsistent. Some research suggests that women may be psychologically more vulnerable than men to a marital status transition (Horwitz et al. 1996; Simon 2002), whereas other research indicates that exiting marriage has a more adverse effect on the mental health of men than women (Carr 2004; Williams 2003). This discrepancy may be the result of using samples in studies that differ in the length of time divorced and in the choice of control variables (Umberson et al. 2013).

In the context of widowhood and gender, the results of research are more consistent in terms of showing more adverse mental health consequences for men than for women (Stroebe et al. 2001; Umberson 1992; Umberson et al. 1992). Additionally, research analyzing the short-term influence of marital status transition on mental health indicated that depressive symptoms observed among women in longitudinal explorations have not differed than men's in short-term research. As scholars inferred, the worse mental condition of women in the long-term perspective was not necessarily caused by marital status transition, but rather by such factors as the decline of socio-economic status after a spouse's death or becoming a single parent. This study also indicated that the level of psychological anxiety among divorcees and widowers is on average $36 \%$ higher compared to people whose marital status has not changed (Strohschein et al. 2005).

In Poland, a limited amount of research has been conducted with regard to the correlation between marital status transition and health, as well as life satisfaction. It has been shown that both divorced females and males assess their health condition as worse compared to married people. The results of Rydzewski's study using the data from the 1990s showed that married people were characterized by a higher mental health state compared to divorced people. Moreover, divorcees were characterized by a lower selfassessment of the quality of life measured by factors such as life satisfaction and life optimism, while it turned out that among divorced people, there were only $10.9 \%$ of fully life optimists compared to $19.6 \%$ in the group of married people. These declarations changed, albeit slowly, over the years because in the first decade of the twenty-first century the rate of unhappy and quite unhappy people among those married and divorced was $10.8 \%$ and $39.2 \%$ respectively. By comparison, during the $1990 \mathrm{~s}$, the rate of unhappy and quite unhappy among married and divorced was $16.6 \%$ and $47.5 \%$ respectively. However, the differences between women and men in terms of physical and mental consequences of divorce have not been observed (Rydzewski 2010), which did occur in the case of a spouse's death. According to other research, the death of a spouse causes more mental and physical problems among men than women (Tobiasz-Adamczyk 2009). It has also been noted that divorce is associated with less negative effects on health condition compared to a spouse's death because $84 \%$ of widowers reported health problems in comparison with $63 \%$ of divorcees (Raciborski 2012). In turn, Szukalski's study (Szukalski 2007) indicated that the rate of mortality was higher among those divorced and widowed than among those continually married, regardless of their age.

There is no previous research which particularly concerns the correlation between marital status change and the quality of life, although the relationships between marital status transitions and life satisfaction (Chipperfield and Havens 2001; Gustavson et al. 2012; Lucas 2005; Naess et al. 2015) or subjective well-being (Kamp Dush and Amato 
2005; Soons et al. 2009) were explored. Referring to these studies, it could be stated that people in marriage/cohabitation are characterized by a higher rate of life satisfaction than those unattached (Chipperfield and Havens 2001; Kamp Dush and Amato 2005; Naess et al. 2015; Soons et al. 2009). In the case of marital transition, widowed and divorced people are characterized by a lower rate of life satisfaction compared to those who are still married (Gustavson et al. 2012; Naess et al. 2015). In turn, among widowers' life satisfaction is lower than their female counterparts (Chipperfield and Havens 2001; Naess et al. 2015).

In our research we use health-related quality of life (HRQoL) defined as the degree of satisfaction or dissatisfaction felt by people with regard to various aspects of their lives (Bowling 2001). The previous studies showed that the terms subjective well-being and life satisfaction used in relation to marital status change measured only psychological quality of life (Medvedev and Landhuis 2018). In the context of life satisfaction Chipperfield and associates (Chipperfield and Havens 2001) used, for instance, LSIA index consisted of 20 items, designed to measure five dimensions of life satisfaction: zest for life; resolution and fortitude; congruence between desired and achieved goals; positive self-concept and mood tone. Gustavson and colleagues (Gustavson et al. 2012) used, in turn, the five-item satisfaction with life scale (SWLS), whereas life satisfaction in Næss et al. research (Næss et al. 2015) was measured by single-item question: 'Considering how you feel these days, are you generally satisfied with your life, or are you generally dissatisfied?'(seven-step bipolar scale varying from very satisfied to very dissatisfied). Subjective well-being in Kamp Dush and associates' research (Kamp Dush and Amato 2005) was assessed with four measures: life satisfaction, general happiness, distress symptoms and self-esteem.

HRQoL, in our view, is the broader concept than previously mentioned as it encompasses the physical (ability to perform daily activities and physical roles, impaired function, pain), psychological (depression, anxiety, well-being) and social (relationships with others, social support and engagement in social activities) domains of health (Bowling 1997, 2001; Raggi et al. 2016). Social well-being as a key component of this paradigm is understood as the possibility of receiving both emotional and practical support which is satisfying for an individual (Tobiasz-Adamczyk 2013). Additionally, the health-related quality of life perspective was not previously analyzed in the context of marital status change therefore our research is the contribution to current studies concerning this topic.

In terms of the theory used with relation to life satisfaction/well-being and change in the marital status, the results of previous studies are inconsistent. According to some of them, the social selection theory is more useful because the lower level of life satisfaction among divorcees is due to the greater tendency of less satisfied people to getting divorced (Lucas 2005; Naess et al. 2015). Other reports show greater support for the social causation theory in the context of subjective well-being claiming that the transition to separation/divorce or widowhood is associated with the negative effects across a number of dimensions of well-being (Kamp Dush and Amato 2005; Marks and Lambert 1996). In turn, Gustavson et al. (2012) in their longitudinal explorations found support for both the causation and the selection theories showing that divorced people were characterized by the significantly lower levels of life satisfaction than those who had stayed together, yet not lower than people having new partners. In conclusion, they stated that the negative association between divorce and life satisfaction could be partially explained by selection effects. 


\section{Main Research Questions}

The aim of this study is to analyze the association between transition out of marriage, physical and mental health as well as health-related quality of life among Polish females and males. Transitions are defined by us as movements out of marital status, which mark important changes in identity or social roles (Dupre and Meadows 2007).

Our research explores the short-term effects of marital status change considered as a stressful life event on physical and mental health, as well as HRQoL. Stress is defined by us as an individual's general feeling of upset or unease as a response to a traumatic life event - widowhood or divorce/separation (Miller et al. 1998). The study is focused on two types of marital transition: 1) married/cohabitating into divorced/separated, 2) married/cohabiting into widowed. We decided to combine marital and cohabiting couples into one category due to three main reasons. Firstly, in our research the percentage of cohabitants turned out to be very low; secondly, there is an increased rate of informal relationships in modern-day Poland, as has been mentioned previously; thirdly, these two types of unions could be considered as comparable because, as previous research indicates, both marriage and cohabitation have a protective effect against bad health (Wu et al. 2012; Zella 2017).

Previous research clearly showed that there is still a lot to discover about the correlation between transition out of marriage, health and HRQoL among females and males. It is also worth mentioning that the majority of previous studies concerning relationship between transition out of marriage and health have been conducted in Western countries, especially in the Anglophone context, whereas our research refers to Eastern Europe (Poland) which has not been sufficiently explored in terms of such a phenomenon. Another advantage of this study is the fact of taking account of the factors encompassing both the physical and mental health of our respondents. Thus, the main research questions are as follows:

1. Are there differences in physical and mental health, as well as health-related quality of life that are due to making a marital transition, i.e. from married/cohabiting to separated/divorced status, married/cohabiting to widowed status compared to the remaining married/cohabiting?

2. Do marital status changes, such as divorce/separation and widowhood have different effects concerning health and HRQoL among females and males?

\section{Methods}

\section{Selection of Participants}

The data comes from the first and the second wave of the COURAGE-Poland population-based study from 2011 (baseline) (Leonardi et al. 2014; Miret et al. 2014) and 2015-2016 COURAGE-POLFUS (follow-up). Participants were randomly selected from a non-institutionalized adult population (18+) based on the multi-stage clustered design with the oversampling of adults aged 50-79 years and $>80$ years. In total, 4071 Polish citizens agreed to participate in the first wave of the study (the response rate was $66.5 \%$ ). Overall, 1850 respondents participated in the second wave. 
In both waves, face-to-face interviews were conducted at the homes of respondents by specially trained interviewers. The study was approved by the Bioethical Committee, Jagiellonian University, Krakow, Poland (No. KBET/208/B/2010; No. 122.6120.26.2015).

We explored a group of 1073 people who were married or cohabiting during the first wave of the study and had changed their marital status prior to the second wave because of a divorce or separation (together as a category that transitioned to a divorced life) or because of becoming widowed (as a category that transitioned to a widowed life/widowhood). Likewise, a group of people who have not changed their marital status and who reported being married or cohabiting (the percentage of cohabited participants was $2.98 \%$ ) was analyzed in both waves, which is included in the analysis (as a category of those continuously married). We will use the names: Transitioned to a divorced life; Transitioned to a widowed life and Continuously married to refer to these categories. The variable we called 'marital status change' with abbreviation MSC. The selection of participants is presented in Fig. 1.

\section{Measurements}

\section{Dependent Variables}

WHO Disability Assessment Schedule (WHODAS II) 12-item version was used as a generic measure of health and disability assessment (Üstün et al. 2010). It was based on the ICF biopsychosocial conceptual model and the global score covers six domains of

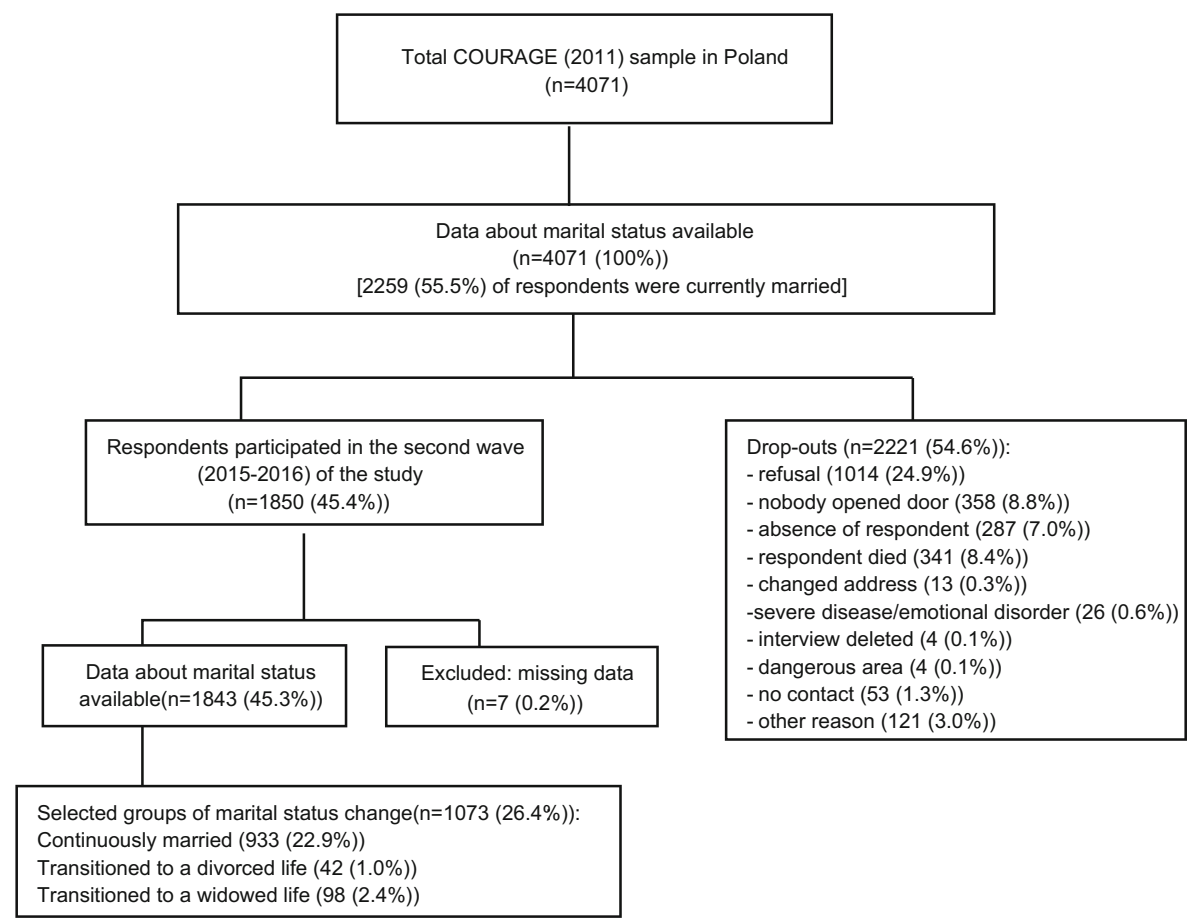

Fig. 1 The selection of participants 
functioning: cognition, mobility, self-care, getting along, life activities and participation. Items assessed the level of difficulties in relation to aforementioned domains of functioning. Responses for every item were "none", "mild", "moderate", "severe" and "extreme". The final score was calculated by the sum of the scores of the items across all domains according to the WHO guidelines and then converting into a metric ranging from 0 to 100 points, where higher score means higher level of disability (WHODAS 2.0.).

The presence of depression was assessed based on the Composite International Diagnostic Interview (Haro et al. 2006) and the DSM-IV criteria for Major Depressive Disorder (American Psychiatric Association 1994). Based on the data from both waves, variables with the following categories were created: 1 - depression present in the first wave, yet not in the second, 2 - the reverse, 3- depression present in both waves, 4 respondents had no symptoms and were not diagnosed for depression at the time of the survey.

Current study contributes to the current knowledge the WHOQOL tool regarded as a measure of HRQoL. This instrument was developed as an international multidimensional tool reflecting the holistic approach to health and health care. It covers six dimensions such as physical and psychological domains, level of independence, social relationships, environment and spirituality/ religion/ personal beliefs (THE WHOQOL GROUP 1995). The health-related quality of life was measured by the Polish version of thirteen items of the WHOQOL-AGE scale. The tool contains items from EUROHIS-QOL (items related to the following domains of quality of life: physical, psychological, social relationships and environment) and WHOQOL-OLD (items related to the following domains of quality of life: sensory abilities, autonomy, past, present and future abilities, social participation and intimacy) scales (Dalgard 1996; The WHOQOL Group 1998), (Power et al. 2005; Zawisza et al. 2014). The final score ranged from 0 to 100 points, whereby a higher score of WHOQOL-AGE is interpreted as better health-related quality of life (Caballero et al. 2013; Zawisza et al. 2016).

\section{Covariates}

The structure of social networks was measured by the COURAGE Social Network Index (COURAGE-SNI) developed as a multi-dimensional instrument which assesses elements of the functionality of social networks (frequency of direct contact, ties and social support) in eight structural components (spouse or partner, parents, children, grandchildren, other relatives, neighbours, friends and co-workers) (Zawisza et al. 2015).

The prevalence of angina, arthritis, asthma and chronic obstructive pulmonary disease were analyzed based on algorithms while taking account of the diagnosis and symptoms (Moussavi et al. 2007). The prevalence of diabetes and stroke symptoms was estimated based on self-reported data about the diagnosis of these diseases. Additionally, an injury was considered as a disease when respondents who had injury and suffered a physical disability as a result of being injured in the last 12 months. For further analysis respondents were grouped on the basis of their disease status into two categories: respondents had some of the afore-mentioned conditions or had none of them. 
Socio-demographic characteristics included the following: gender, age, level of education (primary education, vocational or high school, university degree), total household income per person per year in 1000 Euro and area of residence (urban, rural).

\section{Statistical Analysis}

In order to find differences in socio-demographic and health characteristics between three marital status change categories, Pearson chi-square tests were used for factorial variables and Kruskal-Wallis or U Mann-Whitney tests for continuous ones. In order to see whether the changes of quality of life or health and disability assessment during the follow-up are significant, paired t tests were used. Variables significantly differentiate the MSC categories were considered as covariates for further analysis.

In the case of health and disability assessment, the normal distribution assumption was violated because of strong right skewness. Therefore, the Generalized Linear Mixed Model (GLMM) was used to assess the changes and differences of disability assessment between the categories of marital status change.

Multinomial logistic regression was conducted to see whether marital status change is somehow connected with getting depression. Significance of the differences between men and women in regression coefficients were also tested (Allison 1999).

Then, an analysis of the variance of quality of life was conducted as ANOVA mixed effects models with repeated measure to compare the changes and differences of quality of life between MSC categories. While not every model meets the assumption of normal distribution, the sizes of the samples were sufficiently big for such cases to let us analyze them. In the case of obtaining a significant effect post-hoc Bonferroni tests or pairwise comparisons with Bonferroni correction were analyzed.

The analysis was conducted in the following steps: 1 . unadjusted model; 2 . model adjusted for gender and age; 3 . model adjusted for gender, age, the level of education and disease diagnosis; and the final step; 4. model adjusted for variables from step 3 and the level of social network. Subsequently, the analysis of interactions between MSC and considered covariates was performed.

Analyses were conducted with SPSS 24 and R 3.4.3. The adopted level of significance is 0.05 .

\section{Results}

\section{Characteristics of Respondents}

Table 1 presents the characteristics of respondents for three categories of marital status change. The size of the analyzed sample is 1073 , where $87 \%$ are continuously married, 9.1\% are transitioned to widowhood and $3.9 \%$ are transitioned to a divorced life. The group of people who got divorced/separated is on average the youngest, while continuously married are in the middle and those who got widowed are the oldest. Divorced/ separated and continuously married people are better educated than the widowed. The frequency of people diagnosed with a chronic disease is $36 \%$ among those who transitioned to a divorced life, $50 \%$ of the continuously married, while much higher 


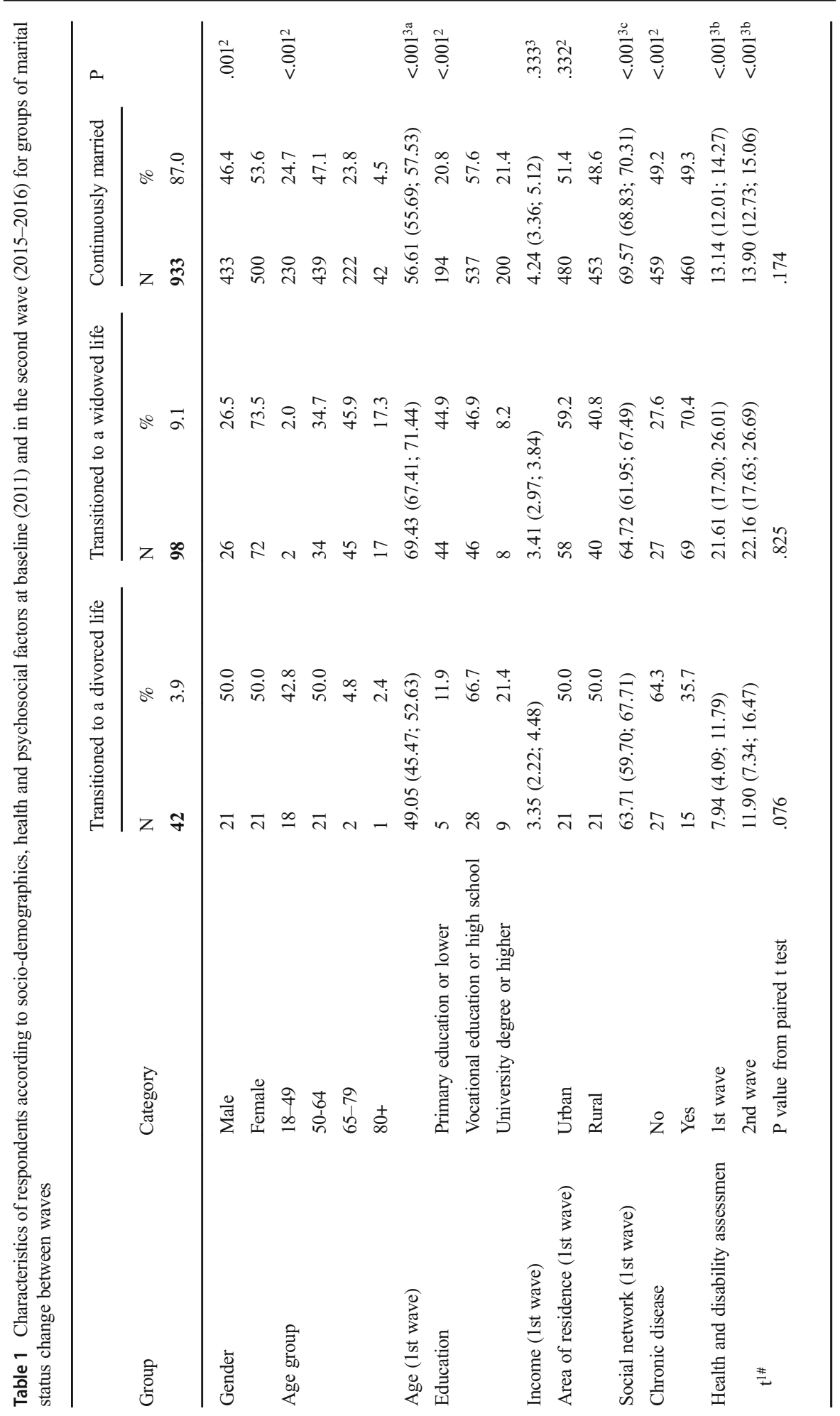




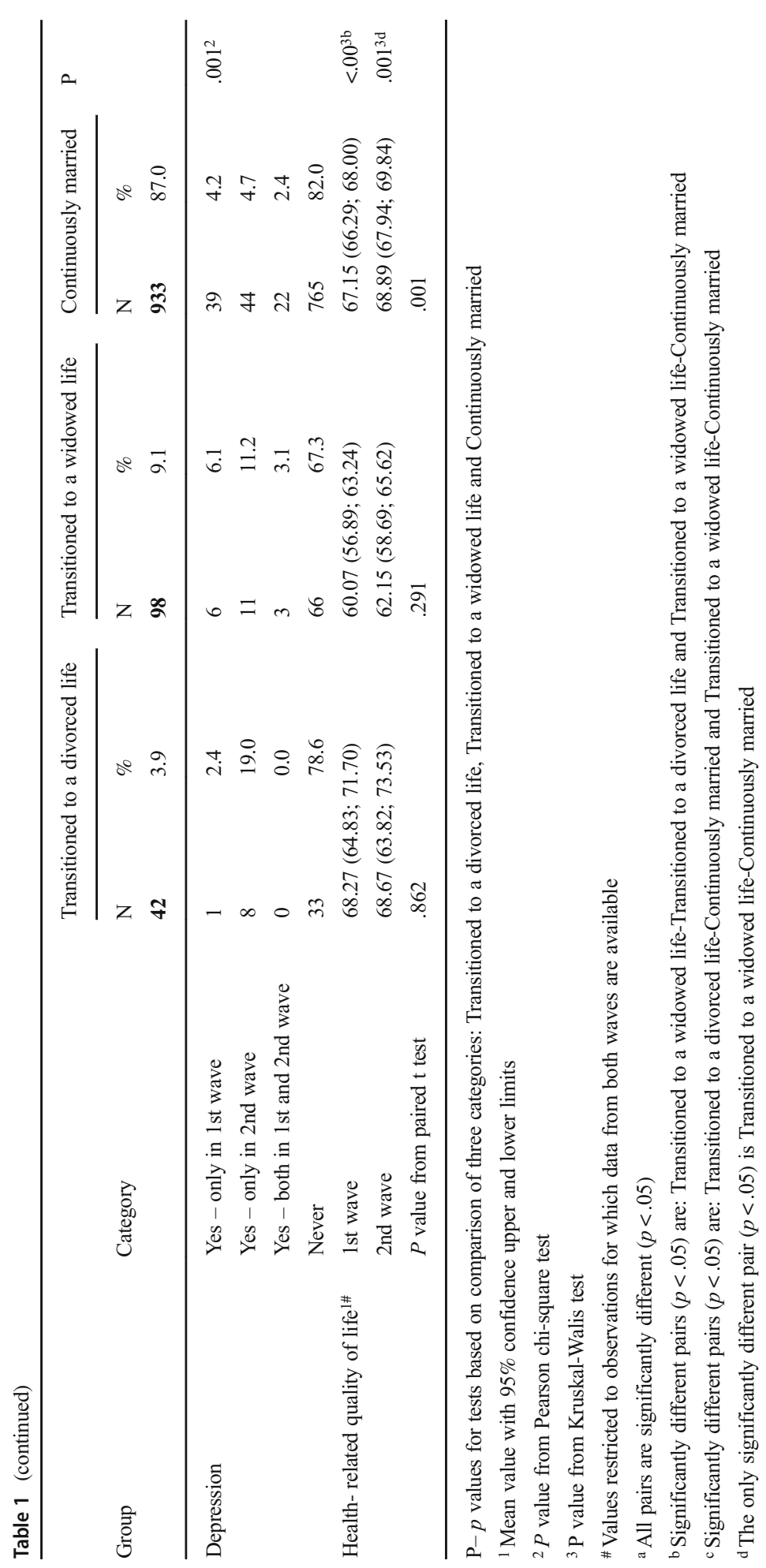


among those widowed (70\%). Continuously married people have got a significantly higher social network level than the other two groups (at about 5-6\%), while the difference between transition to divorced/separated and transition to widowed group is not significant. On the other hand, there are no significant differences in the area of residence and income per person among all three MSC categories.

\section{Transition out of Marriage and its Effect on Physical Health and Disability Assessment}

Disability assessment is much higher in the case of those transitioned to widowhood compared with other two MSC categories, while those transitioned to a divorced life and continuously married do not differ significantly (Table 1). The mean values are the lowest for the divorced/separated in both waves $(7.94 ; 11.90)$, while they are much higher for widowed people $(21.61 ; 22.16)$. However, the effect of marital status change on health and disability assessment is not significant in any of the analyzed models (Table 2).

Males and females neither differ significantly in health and disability assessment among divorced/separated, nor among those widowed and continuously married (Table S1). However, those who are widowed have a significantly worse disability assessment than the other two MSC categories among both females and males before their marital status change, whereas only among females after marital status change (Table S1). Neither gender effect, nor the interaction of MSC and gender are significant in the context of disability assessment (Table 2).

Additional analysis showed that the disability assessment increases with the increasing age for every MSC category (Table S2) and decreases with the increasing level of education (Table S3). Diagnosis of chronic disease results in higher disability assessment compared to a group without any disease and differences between them are approximately equal to 10 units among those transitioned to a divorced life, 15 units among those continuously married and even 20 units among those widowed, which is similar in both waves (Table S4). However, the interactions of MSC with age, education level and diagnosis of disease are not significant in the context of disability assessment.

\section{Transition out of Marriage and its Effect on Depression as an Indicator of Mental Health}

Marital status change categories differ significantly in depression. Depression occurred among less than $5 \%$ of those married (in both waves), while it was about 2.5 times more frequent among those widowed and over 4 times more frequent among those transitioned to a divorced life after their marital status change (2nd wave), as shown in Table 1.

Logistic regression analysis (Table 3 ) indicates that the risk of getting depression after marital status change increases both because of becoming divorced/separated $(\mathrm{OR}=5.1$ in a fully adjusted model) and becoming widowed $(\mathrm{OR}=2.2)$, even if we include gender, age, education level, chronic disease diagnosis and social network as covariates. Noticeably, the odds ratio in the case of divorced/separated is more than twice as large as in the case of widowed. The interactions of MSC with gender, age, education level, chronic disease diagnosis and social network are all insignificant in the context of depression diagnosis (Table 4). 
Table 2 Results of generalized linear mixed models of health and disability assessment

\begin{tabular}{|c|c|c|c|c|}
\hline & & GLMM & & \\
\hline Model number & Factor / Interaction & Type of effect & $\mathrm{F}$ & $\mathrm{p}$ \\
\hline 1 & MSC & BSE & 2.49 & .115 \\
\hline \multirow[t]{2}{*}{ 1a } & MSC & BSE & 2.68 & .102 \\
\hline & Gender & BSE & 0.41 & .524 \\
\hline \multirow[t]{3}{*}{$1 b$} & MSC & BSE & 0.00 & .965 \\
\hline & Gender & BSE & 0.66 & .417 \\
\hline & Age & BSE & 45.86 & $<.001$ \\
\hline \multirow[t]{7}{*}{$1 \mathrm{c}$} & MSC & BSE & 0.12 & .727 \\
\hline & Gender & BSE & 0.26 & .608 \\
\hline & Age & BSE & 8.76 & .003 \\
\hline & Education level & BSE & 11.90 & $<.001$ \\
\hline & Diagnosis of disease & BSE & 55.95 & $<.001$ \\
\hline & Number of wave $*$ Age & WSE & 6.77 & .009 \\
\hline & Number of wave $*$ Education level & WSE & 11.89 & .001 \\
\hline \multirow[t]{8}{*}{$1 d$} & MSC & BSE & 0.01 & .944 \\
\hline & Gender & BSE & 0.50 & .479 \\
\hline & Age & BSE & 2.90 & .089 \\
\hline & Education level & BSE & 9.17 & .003 \\
\hline & Diagnosis of disease & BSE & 60.42 & $<.001$ \\
\hline & Social network & BSE & 2.72 & .099 \\
\hline & Number of wave * Age & WSE & 6.90 & .009 \\
\hline & Number of wave $*$ Diagnosis of disease & WSE & 4.33 & .038 \\
\hline \multirow[t]{3}{*}{2} & $\mathrm{MSC}$ & BSE & 3.42 & .065 \\
\hline & Gender & BSE & 0.02 & .899 \\
\hline & MSC * Gender & BSE & 2.17 & .141 \\
\hline \multirow[t]{3}{*}{3} & MSC & BSE & 0.92 & .337 \\
\hline & Age & BSE & 37.28 & $<.001$ \\
\hline & MSC $*$ Age & BSE & 1.00 & .317 \\
\hline \multirow[t]{4}{*}{4} & MSC & BSE & 0.13 & .714 \\
\hline & Education level & BSE & 30.80 & $<.001$ \\
\hline & MSC * Education level & BSE & 0.42 & .516 \\
\hline & Number of wave * Education level & WSE & 30.80 & $<.001$ \\
\hline \multirow[t]{3}{*}{5} & MSC & BSE & 0.07 & .790 \\
\hline & Diagnosis of disease & BSE & 69.33 & $<.001$ \\
\hline & MSC * Diagnosis of disease & BSE & 1.40 & .237 \\
\hline \multirow[t]{3}{*}{6} & MSC & BSE & 0.12 & .728 \\
\hline & Social network & BSE & 4.97 & .026 \\
\hline & MSC * Social network & BSE & 0.00 & .962 \\
\hline
\end{tabular}

MSC Marital status change categories (Transitioned to a divorced life, Transitioned to a widowed life, Continuously married)

$B S E$ Between-subjects effect

WSE Within-subject effect - for GLMM it includes effects of number of wave and effects of its interactions with other factors (only significant given)

$\mathrm{F}$ - value of test statistics 


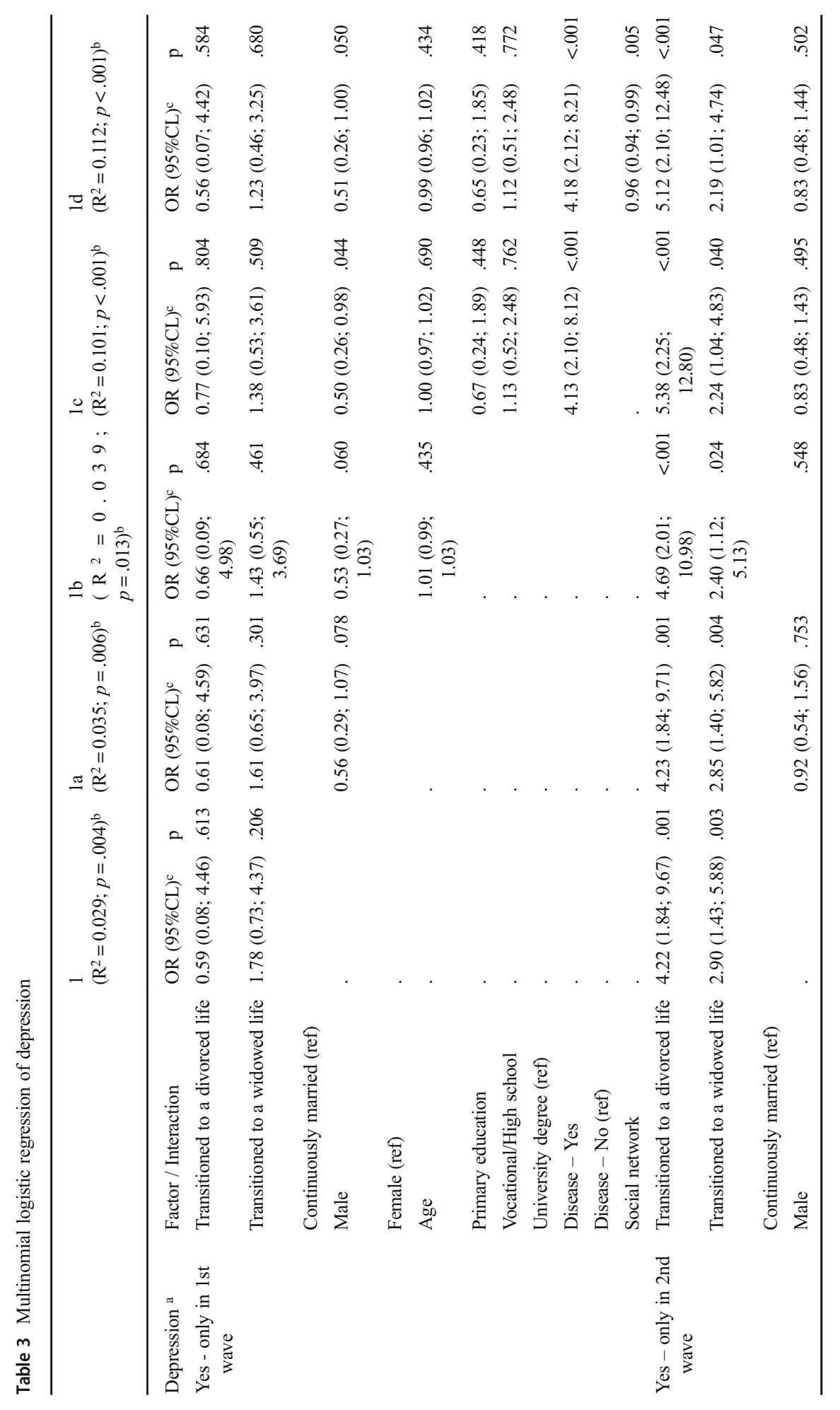




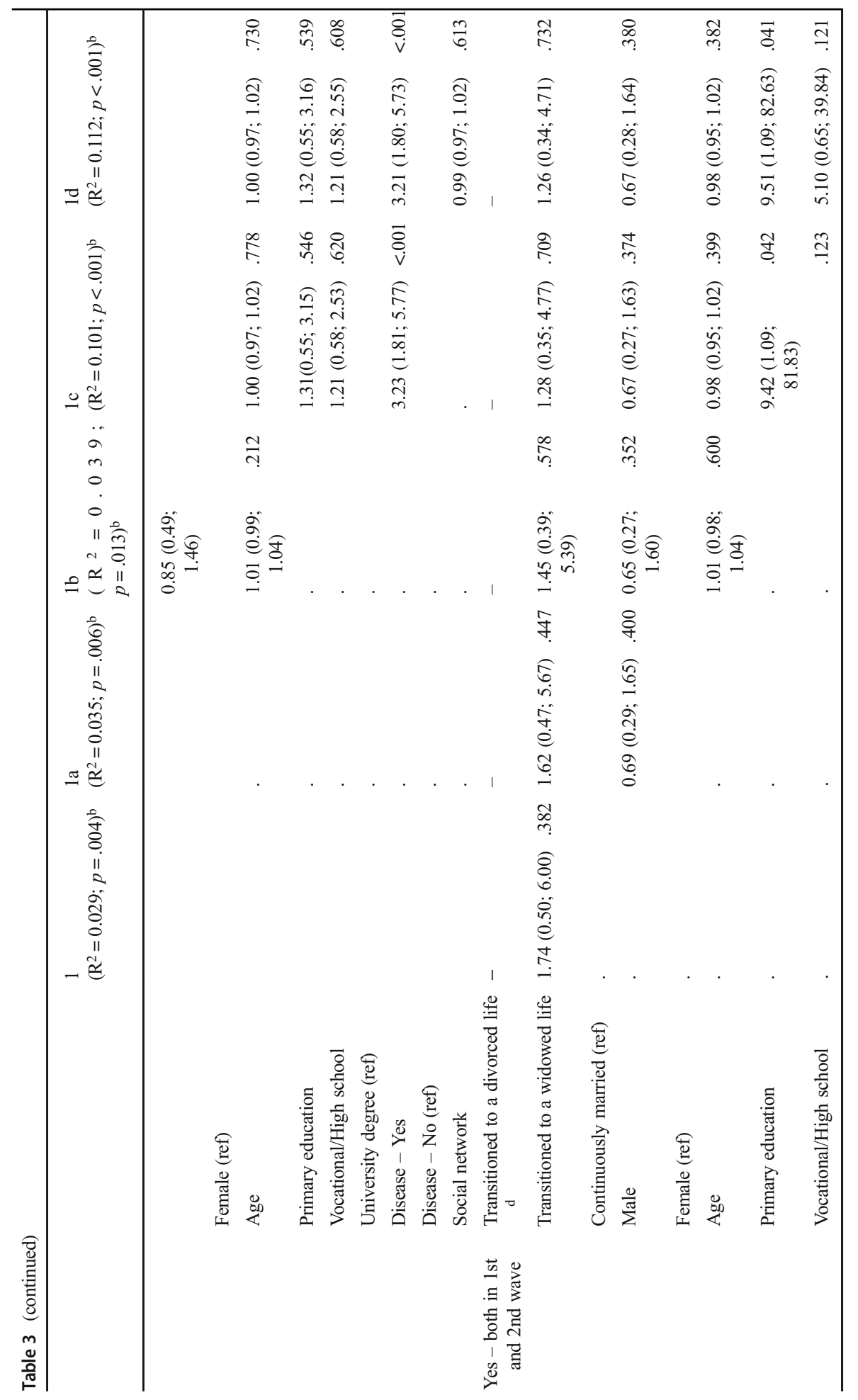




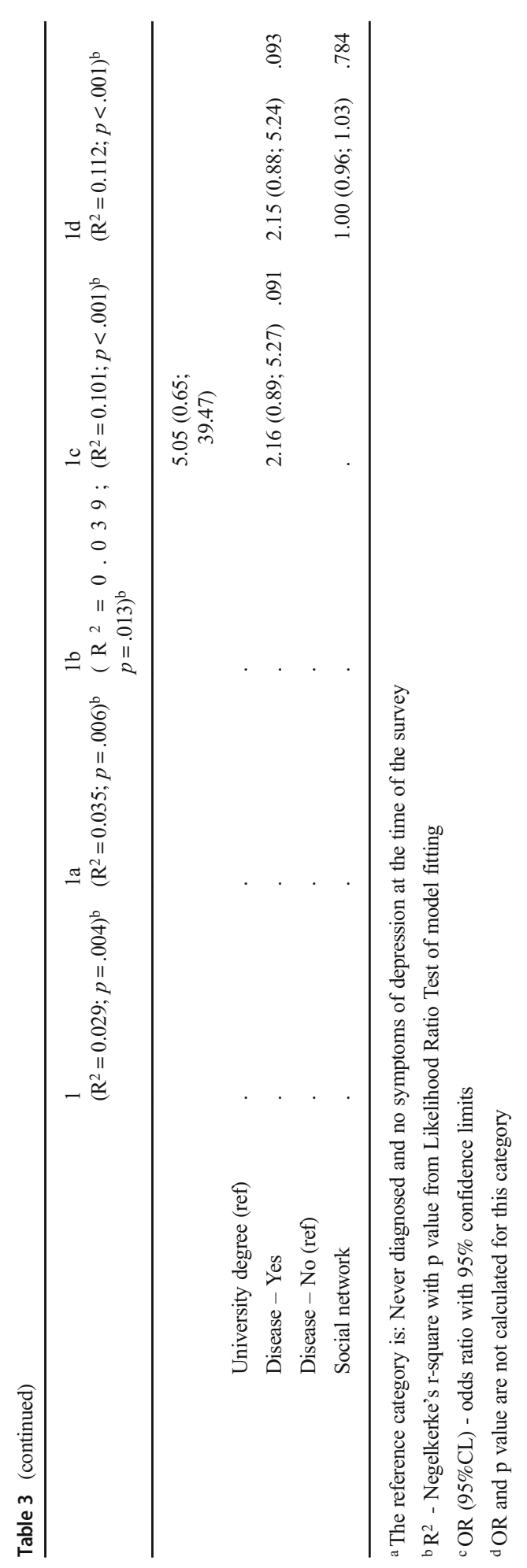




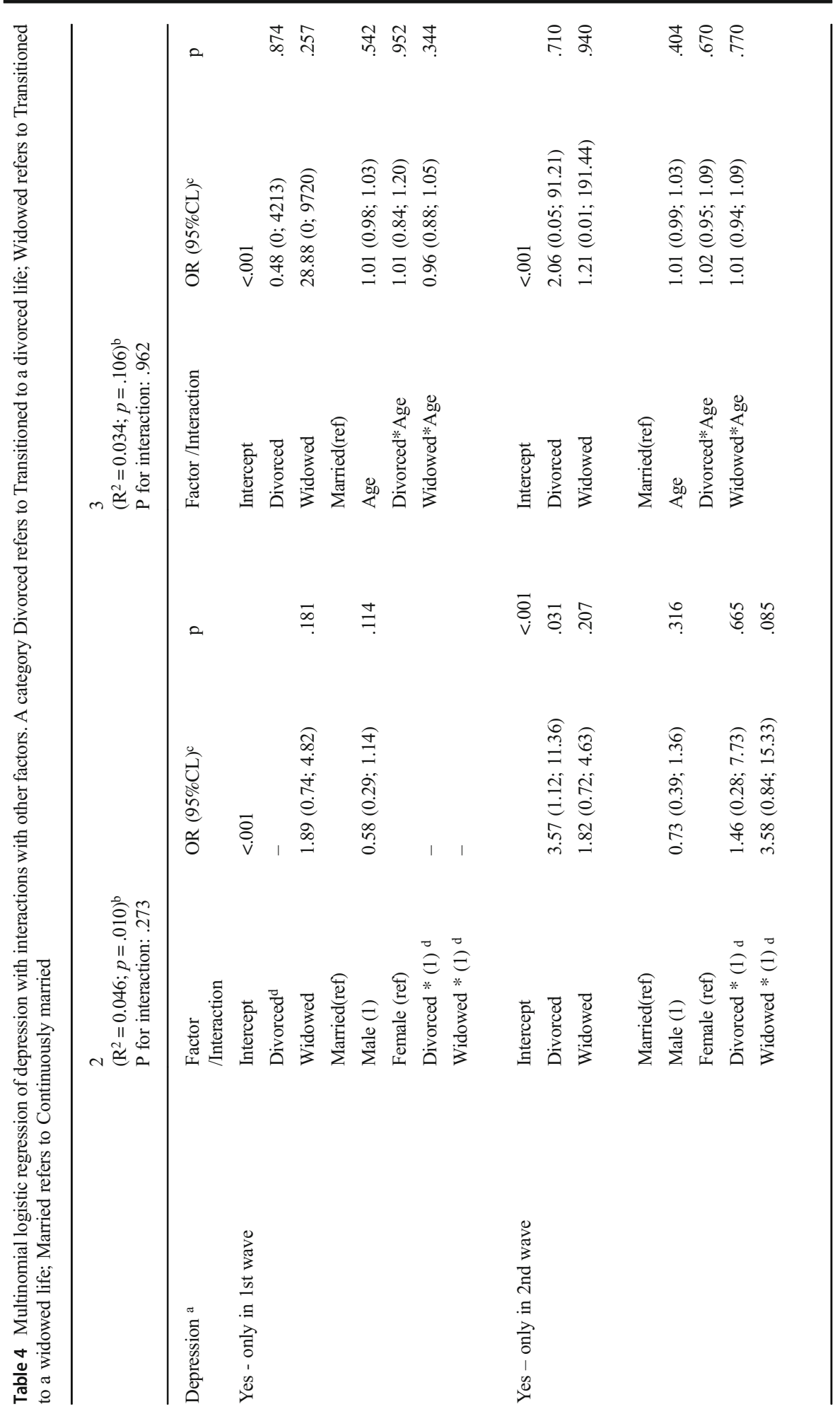




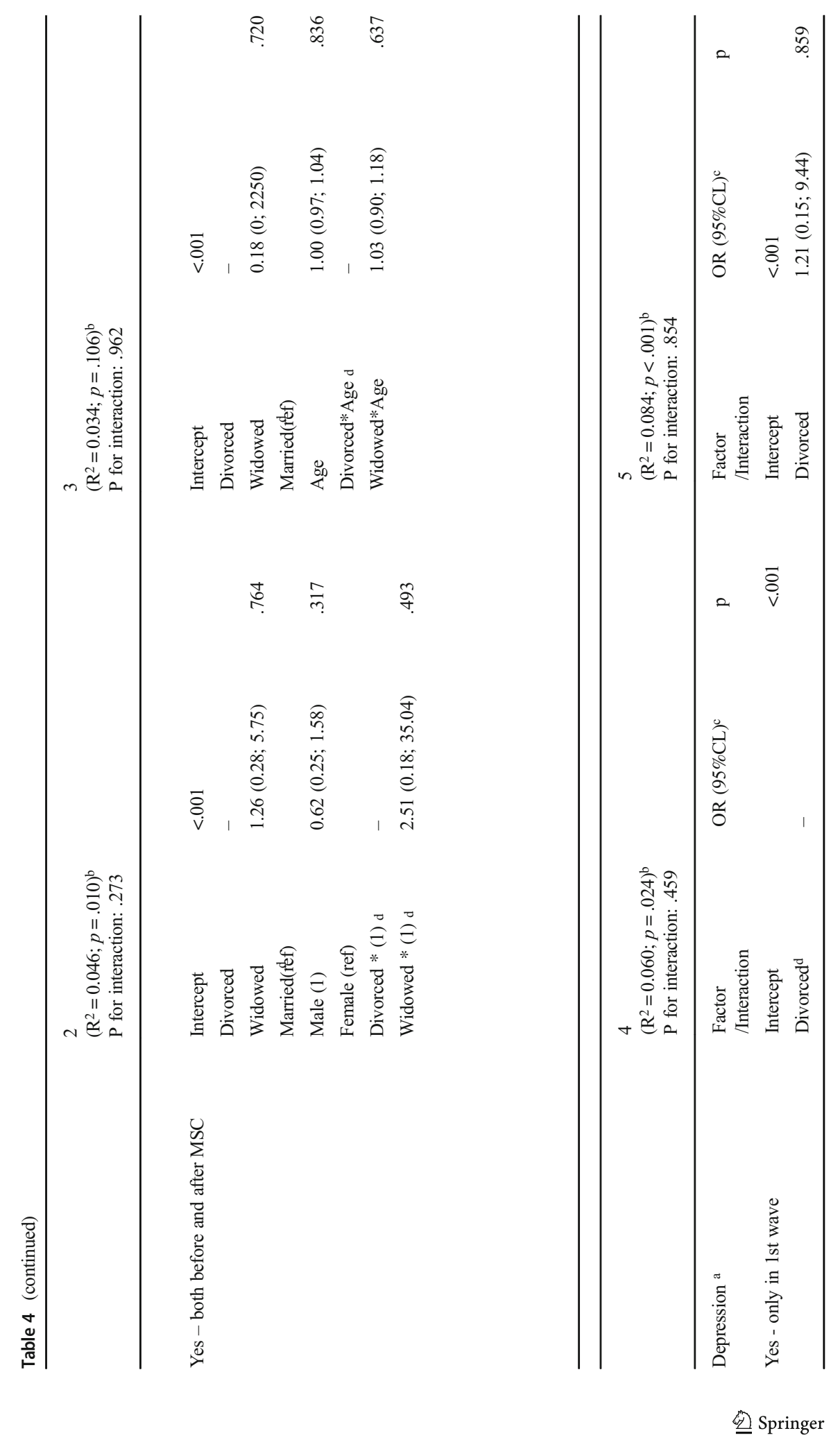




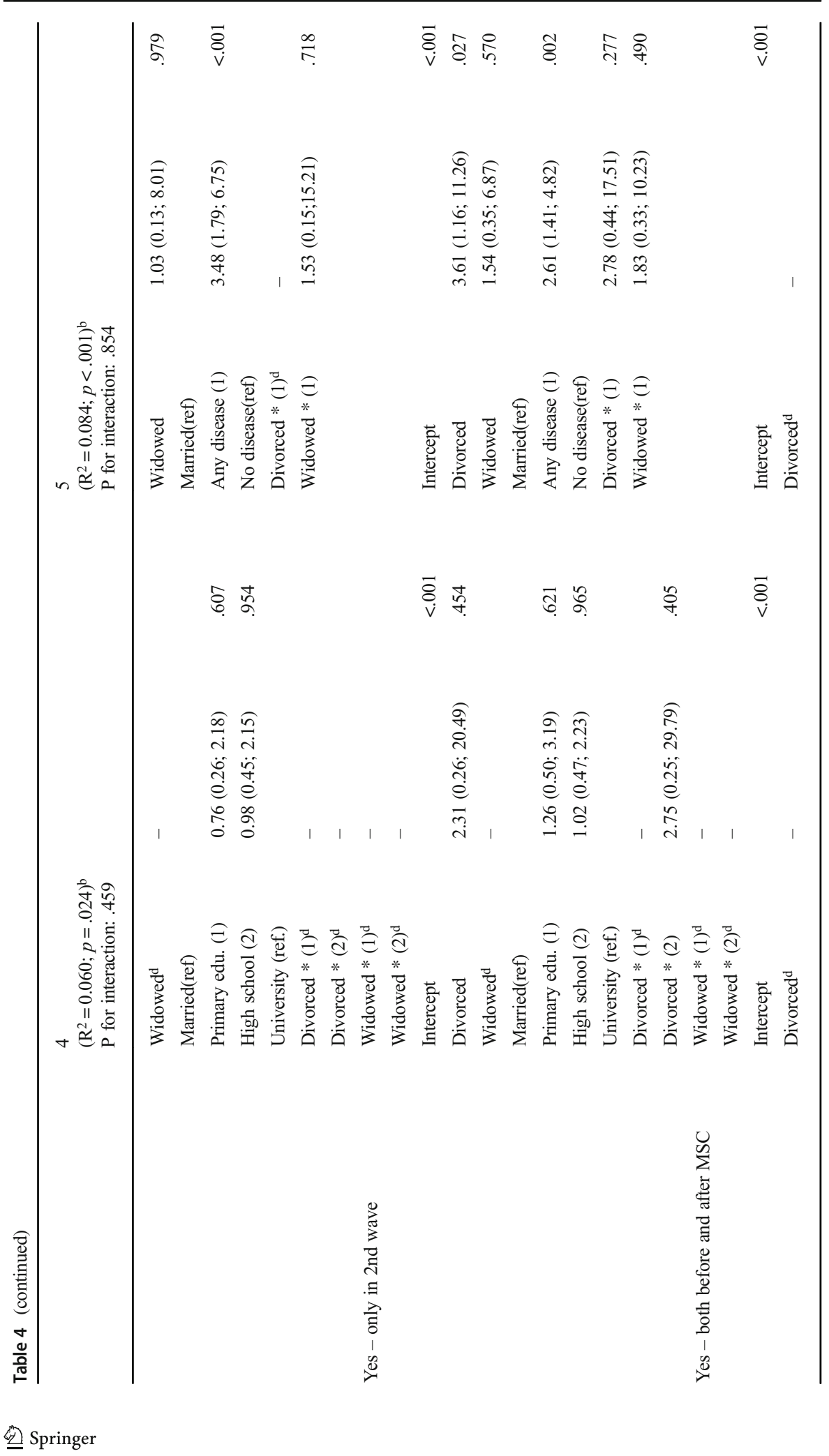




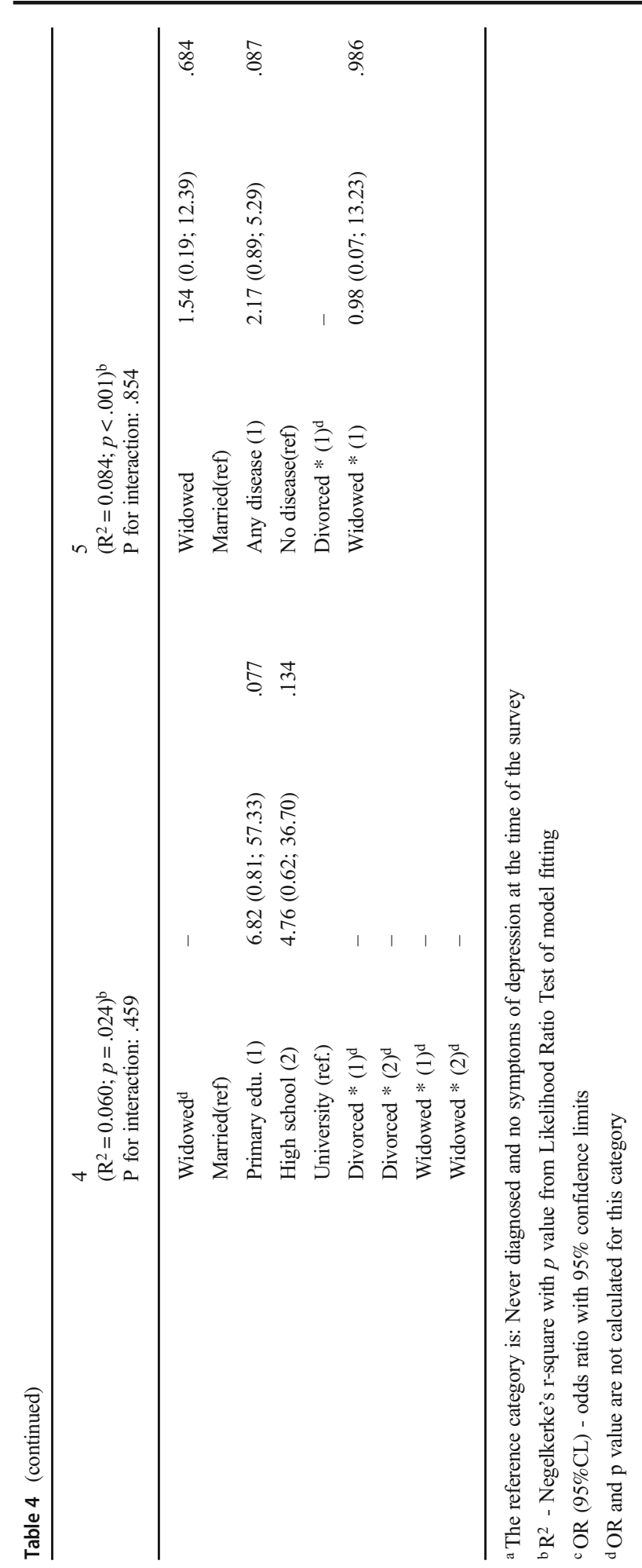


However, analysis of regression models 1 (unadjusted) and 1d (fully adjusted) conducted separately for males and females (Table 5) show that there is a difference between gender in terms of the risk of getting depression at the 2nd wave of the study. For males, the risk of getting depression after marital status change increases both because of getting divorced ( $\mathrm{OR}=6.3$ in a fully adjusted model) and becoming widowed $(\mathrm{OR}=6.4)$, while for females only because of getting divorced $(\mathrm{OR}=5.1$ in a fully adjusted model), but not because of becoming widowed ( $\mathrm{OR}=1.2$ in a fully adjusted model).

\section{Transition out of Marriage and its Effect on Health-Related Quality of Life}

There are significant differences in the health-related quality of life between marital status change categories, as can be seen in Table 1 and presented in Fig. 2 and Fig. 3. The means of the health-related quality of life are the lowest for those transitioned to a widowed life in both waves (60.07 at the 1st wave; 62.15 at the 2 nd wave), while they are much higher for those transitioned to a divorced life and those continuously married both in the first (divorced: 68.27; married: 67.15) and the second wave of the study (divorced: 68.67; married: 68.89). However, the change of the health-related quality of life between the 1 st and 2nd wave is neither significant among those transitioned to a divorced life (difference equal to 0.4 unit; $p=.862$ from paired t test), nor among those transitioned to widowhood $(2.08 ; p=.291)$ (Table 1$)$. The significant effect of marital status change on the health-related quality of life was confirmed by the ANOVA models (unadjusted and adjusted for age and gender) but it may be eliminated by the effects of education level, chronic disease diagnosis or social network (Table 6).

The interaction between MSC and gender remains significant even in a fully adjusted model ( $p=.017$ for the Model 2d). Males who transitioned to a divorced life have a lower quality of life than continuously married males, whereas those transitioned to a divorced life females have a higher quality of life than their continuously married counterparts, as shown in Table S1 and on Fig. 4. Additionally, after a complete adjustment, females transitioned to a widowhood tend to have a higher estimated quality of life than continuously married females, while males transitioned to a widowerhood have a much lower quality of life than the continuously married males, as depicted in Fig. 5.

Additional analysis showed that the health-related quality of life decreases with increasing age for every MSC category (Table S2) and increases with the increasing level of education (Table S3), whereas it is lower for groups with a diagnosis of any chronic disease and higher for groups without any disease (Table S4). Interactions of MSC with age, education level, chronic disease diagnosis and social network are all not significant in the analyzed healthrelated quality of life models (Table 6). Further analysis of the relationship between MSC and HRQoL at the baseline and in the second wave across gender groups was additionally considered and showed that after controlling for age and other covariates, the results are significant only among continuously married and widowed men in the case of the HRQoL measured during the follow-up. The results of the tests are presented in Tables S6 and S7. 


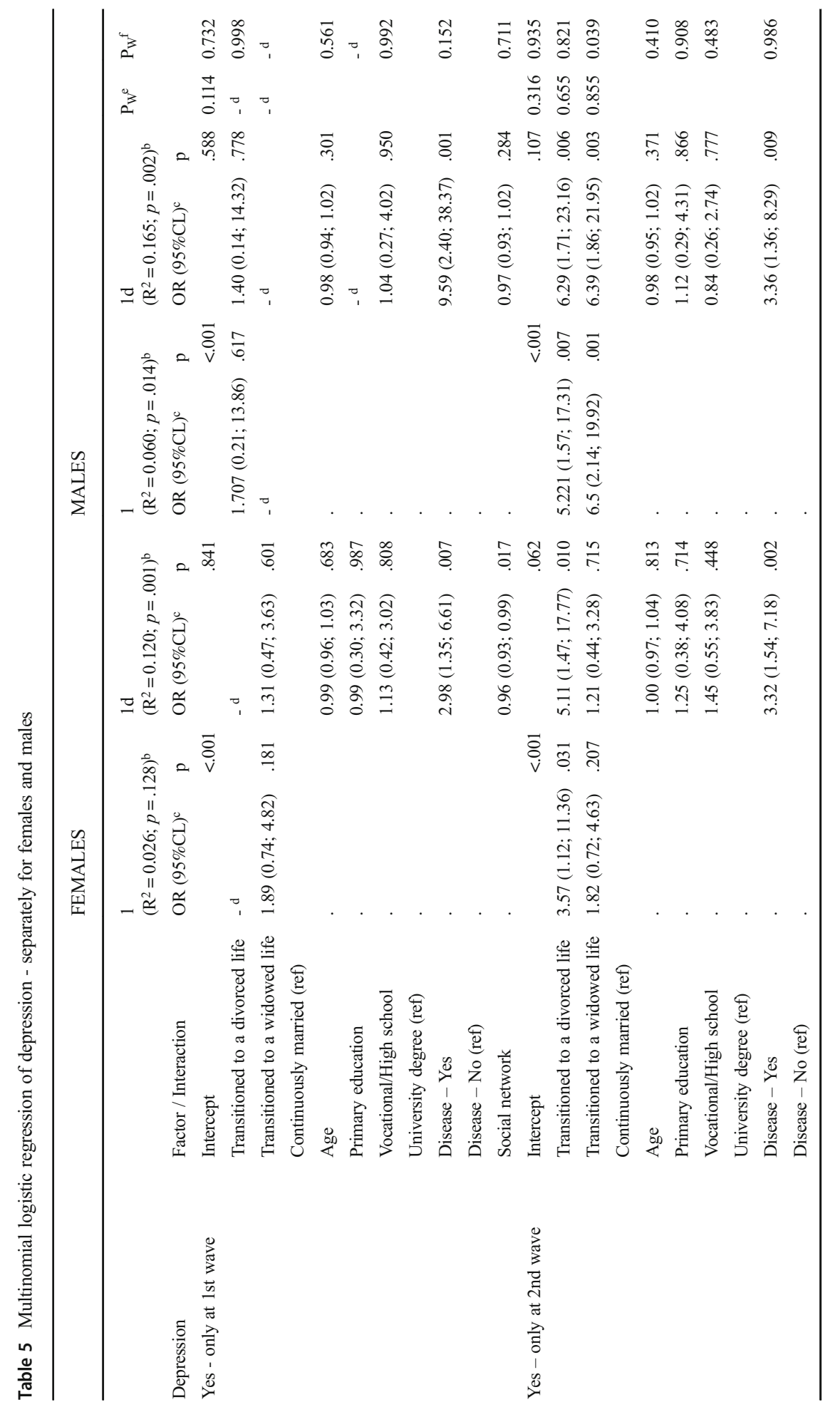




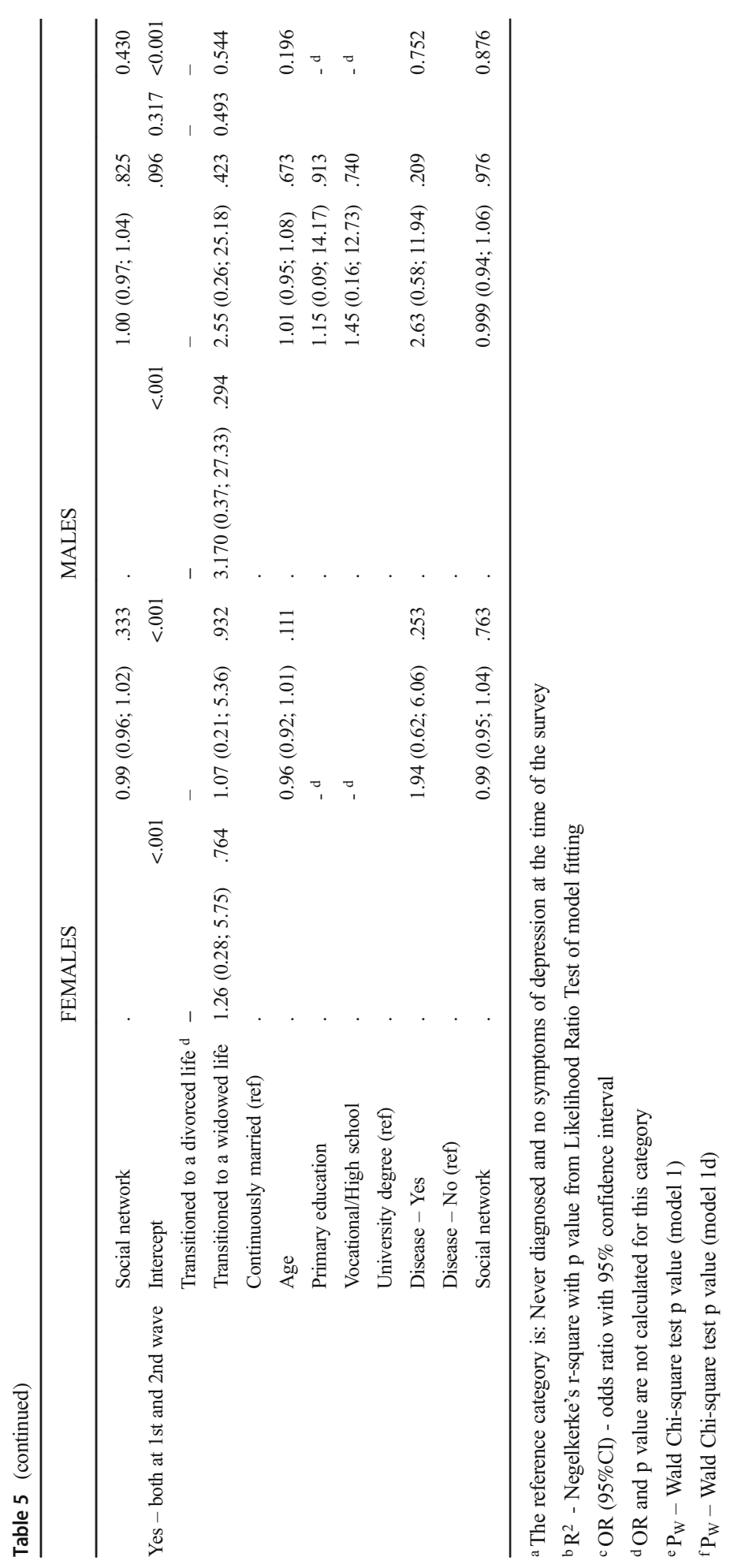




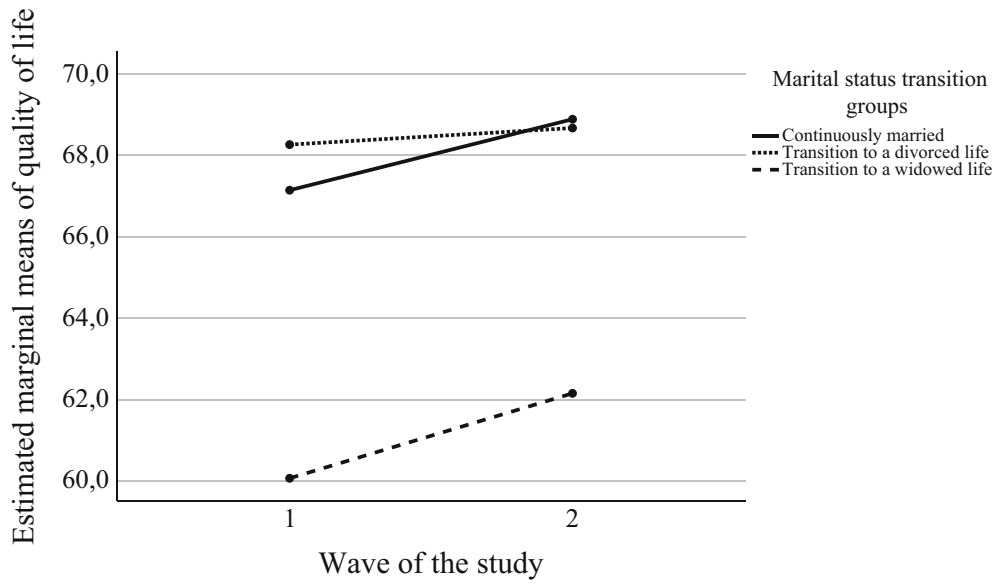

Fig. 2 Health -related quality of life for marital status change categories (unadjusted model)

\section{Discussion}

This longitudinal study examines the relationship existing between marital status transition considered as a stressful life event, physical and mental health, as well as health-related quality of life among Polish females and males based on the first and the second wave of the COURAGE-Poland population survey. The main objective of our research was to find out the extent of the impact the marital status transitions such as divorce/separation or widowhood have on physical and mental health, as well as on health-related quality of life compared to married/cohabiting people, whose marital status has not been changed. Additionally, we wanted to check whether marital status transition has different effects among females and males in the context of their physical and mental health as well as the reported HRQoL.

In the context of disability assessment used as a factor of general health, it could be stated that it is much higher among those transitioned to a widowed life compared to

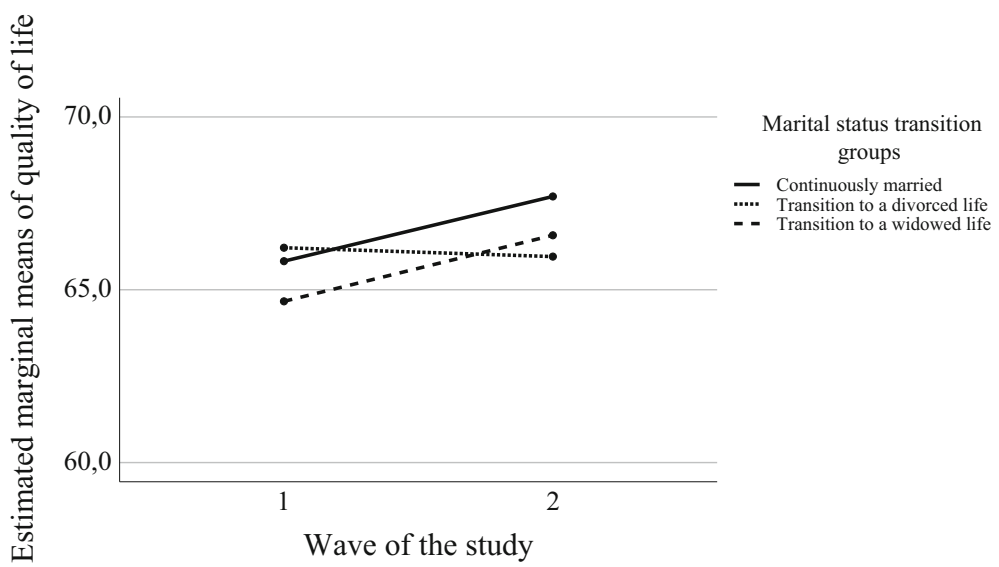

Fig. 3 Health -related quality of life for marital status change categories (fully adjusted model). Covariates appearing in the model are evaluated at the following values (at baseline): Age $=56.72$; Social network $=68.90$ 
Table 6 Results of analysis of variance mixed effects of health- related quality of life

\begin{tabular}{|c|c|c|c|c|}
\hline \multirow[b]{2}{*}{ Model number } & \multirow[b]{2}{*}{ Factor / Interaction } & \multicolumn{3}{|c|}{ ANOVA mixed effects } \\
\hline & & Type of effect & $\mathrm{F}$ & $\mathrm{p}$ \\
\hline 1 & MSC & BSE & 14.50 & $<.001$ \\
\hline \multirow[t]{2}{*}{ 1a } & MSC & BSE & 15.34 & $<.001$ \\
\hline & Gender & BSE & 2.88 & .090 \\
\hline \multirow[t]{3}{*}{$1 \mathrm{~b}$} & MSC & BSE & 3.28 & .038 \\
\hline & Gender & BSE & 0.60 & .440 \\
\hline & Age & BSE & 140.78 & $<.001$ \\
\hline \multirow[t]{5}{*}{$1 \mathrm{c}$} & MSC & BSE & 1.82 & .163 \\
\hline & Gender & BSE & 0.09 & .761 \\
\hline & Age & BSE & 34.42 & $<.001$ \\
\hline & Education level & BSE & 53.37 & $<.001$ \\
\hline & Diagnosis of disease & BSE & 65.14 & $<.001$ \\
\hline \multirow[t]{8}{*}{$1 d$} & MSC & BSE & 0.58 & .560 \\
\hline & Gender & BSE & 0.01 & .925 \\
\hline & Age & BSE & 26.12 & $<.001$ \\
\hline & Education level & BSE & 55.94 & $<.001$ \\
\hline & Diagnosis of disease & BSE & 65.03 & $<.001$ \\
\hline & Social network & BSE & 47.51 & $<.001$ \\
\hline & Number of wave & WSE & 6.10 & .014 \\
\hline & Number of wave * Social network & WSE & 10.99 & .001 \\
\hline \multirow[t]{3}{*}{2} & MSC & BSE & 17.62 & $<.001$ \\
\hline & Gender & BSE & 11.48 & .001 \\
\hline & MSC * Gender & BSE & 4.44 & .012 \\
\hline \multirow[t]{4}{*}{$2 b$} & MSC & BSE & 5.65 & .004 \\
\hline & Gender & BSE & 4.27 & .039 \\
\hline & MSC * Gender & BSE & 4.36 & .013 \\
\hline & Age & BSE & 140.33 & $<.001$ \\
\hline \multirow[t]{6}{*}{$2 \mathrm{c}$} & MSC & BSE & 3.45 & .032 \\
\hline & Gender & BSE & 3.36 & .067 \\
\hline & MSC * Gender & BSE & 3.20 & .041 \\
\hline & Age & BSE & 34.85 & $<.001$ \\
\hline & Education level & BSE & 51.55 & $<.001$ \\
\hline & Diagnosis of disease & BSE & 65.80 & $<.001$ \\
\hline \multirow[t]{9}{*}{$2 d$} & MSC & BSE & 2.29 & .102 \\
\hline & Gender & BSE & 4.15 & .042 \\
\hline & MSC * Gender & BSE & 4.12 & .017 \\
\hline & Age & BSE & 26.49 & $<.001$ \\
\hline & Education level & BSE & 54.01 & $<.001$ \\
\hline & Diagnosis of disease & BSE & 66.07 & $<.001$ \\
\hline & Social network & BSE & 49.33 & $<.001$ \\
\hline & Number of wave & WSE & 5.38 & .021 \\
\hline & Number of wave $*$ Social network & WSE & 10.42 & .001 \\
\hline
\end{tabular}


Table 6 (continued)

\begin{tabular}{lllll}
\hline \multicolumn{4}{l}{ ANOVA mixed effects } \\
\hline 3 & MSC & BSE & 0.58 & .558 \\
& Age & BSE & 36.69 & $<.001$ \\
MSC * Age & BSE & 1.15 & .318 \\
4 & BSE & 4.82 & .008 \\
MSC & BSE & 18.65 & $<.001$ \\
Education level & BSE & 0.48 & .752 \\
MSC * Education level & BSE & 8.83 & $<.001$ \\
& MSC & BSE & 28.26 & $<.001$ \\
& Diagnosis of disease & BSE & 0.17 & .845 \\
MSC * Diagnosis of disease & BSE & 0.15 & .858 \\
MSC & BSE & 17.50 & $<.001$ \\
& Social network & BSE & 0.07 & .929 \\
MSC * Social network & WSE & 7.56 & .006 \\
& Number of wave & WSE & 6.08 & .014 \\
\hline
\end{tabular}

MSC Marital status change categories (Transitioned to a divorced life, Transitioned to a widowed life, Continuously married)

$B S E$ Between-subjects effect

WSE Within-subject effect (only significant given in the table)

$\mathrm{F}$ - value of test statistics

the other two MSC categories in both waves of the survey. However, the effect of marital status change on disability assessment turned out to be not significant among those who transitioned to a divorce/separation, and those who transitioned to a widowed life. In accordance with the Williams and Umberson's (2004) study, our research shows that the higher rate of disability assessment characterizes older respondents regardless of MSC category according to the notion that the older suffer physically more than younger people because of the ageing process. Gender in the interaction with marital status change is not significant in terms of the disability assessment which is inconsistent with previous research that claims that marital disruption influences the physical health of men more than women (Lee and DeMaris 2007; Williams and Umberson 2004).

We found a relationship between the marital status and mental health. In the analyzed sample, the odds of getting depression considered as a mental health factor is more than 5 times higher among those transitioned to divorce/separation and more than 2 times higher among those widowed than among those continuously married. These results are in line with the hitherto findings suggesting that the dissolution of a union tends to negatively affect mental health (Amato 2010a; Lamb et al. 2003; Simon 2002; Wilcox et al. 2003). These findings are also consistent with previous Polish research that show worse mental health of divorced and widowed people compared to those married (Rydzewski 2010; Tobiasz-Adamczyk 2009). A possible explanation of the results received could be the statement according to widowhood, using Pearlin's terminology (Pearlin 1989), which is considered as a life event stress, which as 

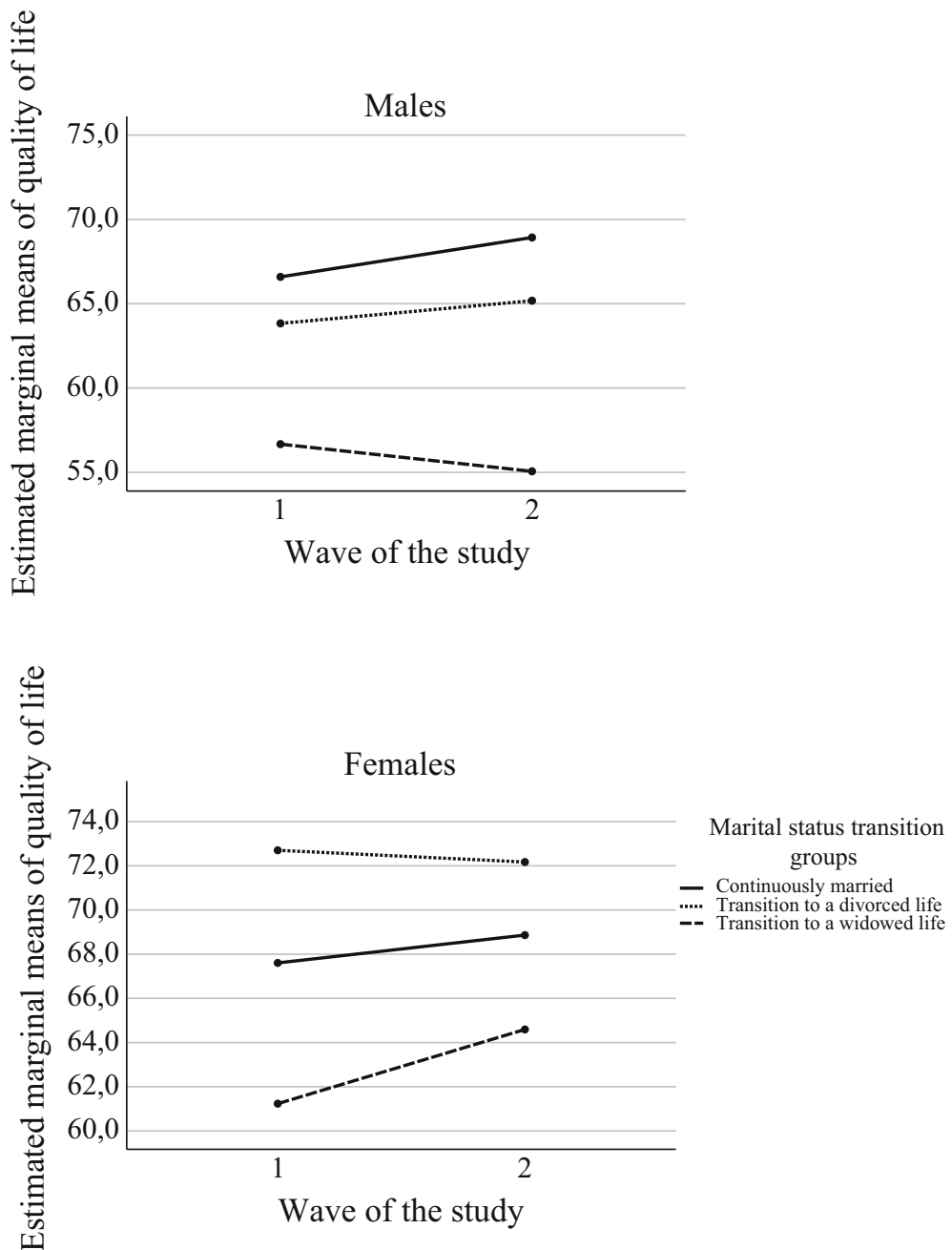

Fig. 4 Health -related quality of life for marital status change categories - males and females for the model with interaction, without adjusting

previous research stated, people generally recover over time (Lee and DeMaris 2007; Wilcox et al. 2003), whereas divorce is regarded as a chronic strain that leads to the loss of resources provided by marriage (Williams and Umberson 2004). Chronic strain tends to have stronger effects on health than a life event since it constitutes a stressful burden that continues over time (Turner 2003). In this perspective, sustained chronic strains, for instance, an economic hardship experienced by divorced people could lead them to the permanent decline in mental health and depression.

In addition, transitions out of marriage exert gender-specific effects on the occurrence of depression. The odds of getting depression among females transitioned to a divorced life was more than 5 times higher compared to their continuously married counterparts. In the case of men, the odds of getting depression turned out to be significantly higher (6 times) among those who transitioned to a divorced life and even 


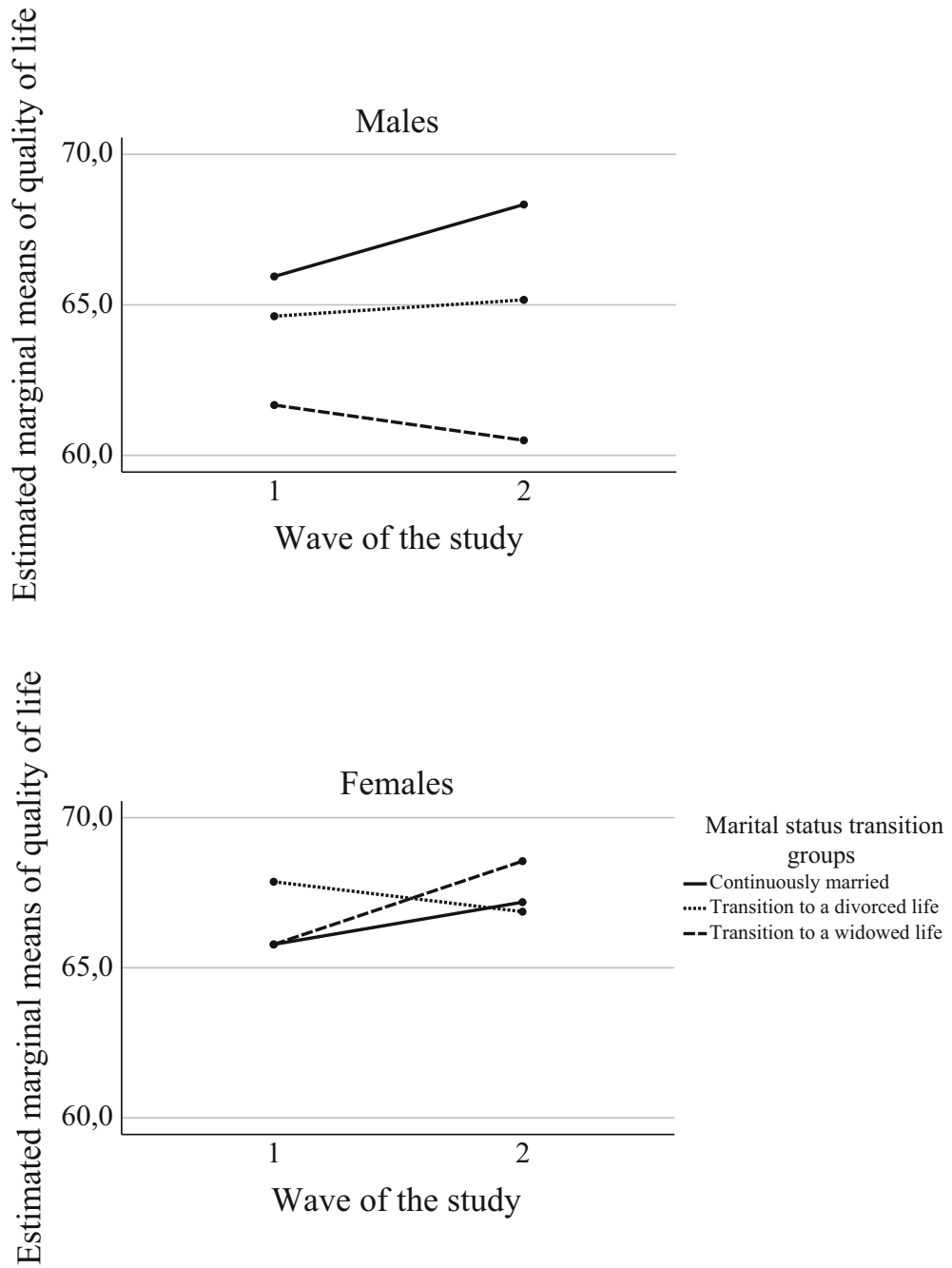

Fig. 5 Health -related quality of life for marital status change categories - males and females for the model with interaction, fully adjusted. Covariates appearing in the model are evaluated at the following values (at baseline): Age $=56.72$; Social network $=68.90$

slightly higher among those who transitioned to a widowerhood compared to continuously married males. These results support the shock theory stressing the impact of stress associated with widowerhood and divorce (Birch 1997; Bruce and Kim 1992; Holmes and Rahe 1967). Our findings also indicate on the correlation according to which measures of mental health among divorced females and males are in general comparable, which is consistent with previous research (Amato 2010). The acknowledged differences among widowed females and males could be explained by referring to previous research according to which men are more vulnerable to depression following widowerhood than women. The main reason for this may be provided by social role theory. According to this, greater social deficits for men after becoming 
widowed and also not having assistance in household management cause their emotional and social isolation (Johnson and Wu 2002; Ross 1995). In turn, women maintain more non-marital relationships which, in the case of a traumatic life event such as widowhood, prevent them from getting depressed (Miller et al. 1998; Umberson et al. 1992). These differences might also be explained by findings according to which many women are their ill husband's caregivers, therefore widowhood might have reduced the mental strain associated with caring for a dying spouse or anticipatory loss (Wilcox et al. 2003).

The analysis of the collected data allows us to conclude that marital status change seems to have a significant connection with the reported health-related quality of life. Higher rates of HRQoL among those continuously married compared to those divorced and widowed groups have been noticed. Furthermore, continuously married people with chronic disease declared a higher rate of health-related quality of life than those who transitioned to a widowed life, which indicates the protective effect of being in a $n$ union during stressful times. However, unlike what was found for depression, the HRQoL rate for those to-be-widowed and to-be-divorced women and men did not significantly change along with marital transitions.

In the 1st wave of the survey, as is showed in the simple model, both to-be-divorced females and males have not been characterized by a significantly different quality of life rate compared to their married counterparts. In contrast, to-be-widowed males and females had significantly lower rates of HRQoL compared to those married because, as we may assume, they were living with ill spouses and perhaps had to care for him or her. After consideration of covariates the results turned out to be not significant. These outcomes were consistent with previous studies that show this relation (Chipperfield and Havens 2001; Naess et al. 2015).

Based on the results presented in the simple model, after marital status change, as could be expected, our findings showed that widowed men and women had a significantly lower quality of life than those continuously married. This relationship concerning widowed and continuously married males turned out to be significant even in a fully adjusted model. It is also worth mentioning that in the 2 nd wave, as has been showed in the simple model, divorced females were characterized by a higher HRQoL rate than their continuously married counterparts. As Gustavson et al. (2012) stated, change into divorce/separation could be considered as a positive for individuals from highly-troubled relationships because remaining in it negatively affects life satisfaction. To-be-divorced females were likely to be living in an unhappy marriage, therefore the dissolution of the union could even be a positive change for them. Moreover, the increasing level of social acceptance for divorce in the case of fraught marriage is the consequence of the secularization process occurring in Western European societies. These trends have also emerged in Polish society because currently one out of three marriages established in Poland lead to divorce (Demographic Yearbook of Poland 2017). This finding also supports the previous Polish research according to current Polish society becomes more and more similar to societies in Western Europe in terms of rate of divorce (Szukalski 2013). Although divorce rate in Poland is still lower compared to Western societies, Szukalski (2013) predicts that in next years would become probably the same because of globalization processes and very strong will of the vast majority of Poles to live like Western Europeans. On these tendencies indicates an increasing number of cohabitations 
among Polish people nowadays which is consistent, as Szukalski (2013) states, with social processes already occurred in Western societies. However, our results are inconsistent with other Polish study suggesting lower life satisfaction and wellbeing among divorced people compared to those married, regardless of their gender (Rydzewski 2010). The lack of significant difference in terms of HRQoL among those divorced and continuously married men and even a higher rate of health-related quality of life among divorced females compared to married women could indicate that divorce might be no longer perceived in Poland as a harmful occurrence, at least to some extent. In this context, our findings seemed to be inconsistent with previous research according to which the lower life satisfaction of divorced people compared to those continuously married is caused by selection effects (Gustavson et al. 2012; Naess et al. 2015).

Our study clearly shows that females transitioned to widowhood report better healthrelated quality of life than their male counterparts. This correlation has also been observed among women transitioned to a divorced life compared to their male counterparts (the difference is significant only before marital status change). Considering all MSC categories, the lowest rate of HRQoL has been noticed among males transitioned to a widowed life in both waves of the survey. These findings are consistent with the results of other studies according to which marital relationships seem to be more rewarding for men than for women (Chipperfield and Havens 2001; Naess et al. 2015). The differences might be interpreted by way of three reasons proved by previous research. Firstly, men usually view their spouse as their only close confidant, therefore widowerhood caused by the loss of this close person may decrease their emotional well-being (Chappell 1989). Secondly, wives tend to receive support from close friends or children, whereas husbands are supported predominantly by their wives (Antonucci and Akiyama 1987). Thirdly, unlike men, women tend to create and maintain social networks providing social support during stressful times which consequently eases the trauma experienced (Taylor et al. 2000).

The education level seemed to be a significant factor in the context of health-related quality of life. Among all MSC categories, HRQoL increases with the increasing level of education, however the interaction of MSC with the education level turned out to be insignificant. Our findings indicate that the highest rates have been noticed among those continuously married and transitioned to a divorced life obtaining university diplomas or higher degrees, whereas the lowest are among those transitioned to a widowed and continuously married status having only a primary level of education. These results could suggest that the education level is a more important factor in terms of the reported HRQoL rather than the transition out of marriage.

The current study indicates that there are differences in the case of HRQoL between the different age categories of respondents, albeit they are not significant either. It could be stated that the lower health-related quality of life has been declared by the oldest respondents transitioned to a widowed life, as well as those transitioned to a divorce (65-79 and 80+) compared to those continuously married which could be explained using socio-emotional selectivity theory (Carstensen 1992). As marriage becomes more salient for older people, exiting from it causes significant decline in the personal quality of life. In contrast, the highest rate of HRQoL has been noticed among the youngest respondents (18-49) in each marital status change category. 


\section{Limitations and Future Directions}

It could be stated that the large randomly selected sample from the general population that allows interaction analyses focusing on different socio-demographic factors, such as age and level of education, as well as the exploration of the two waves of the survey turned out to be the strong point of our research. Moreover, the health-related quality of life perspective which has not been previously explored with relation to marital status change and taking account of both physical and mental health factors are further attributes of our research.

Nevertheless, there are some limitations regarding this study. There are three most important. Firstly, the relatively small number of respondents included in the marital status change groups, secondly, the high drop-out rate between the waves of the survey. The analysis of attrition for this study has shown that individuals who were married or cohabited at baseline and participate in both waves were younger than the second group but there were no significant differences in relation to gender, level of education and self-reported health status. Third limitation concerns the possibility of unmeasured selection effects. Fourthly, the limitation of our study refers to the fact that the explorations were conducted only in two waves, thus we could not check the long-term effects caused by the marital status transition on health and HRQoL which should be considered in future research. Fifthly, we did not have access to the marital history of our respondents whereas, as research shows, there exists a correlation between the accumulated married years and the health status according to which, more years spent in marriage could ease health risks after marital status change (Barrett 2000; Dupre and Meadows 2007).

Future research should also consider the quality of explored relationships because leaving less beneficial unions, regardless of divorce or widowhood, could have an impact on the reported health-related quality of life after transition out of marriage (Gardner and Oswald 2006). Furthermore, we have not considered the influence of secondary stressors such as, for instance, the decline in income or relocating which could take place during marital status change. It is also worth mentioning more factors of physical and mental health in future explorations with relation to transition out of marriage. Despite these potential limitations, our study sheds light on the influence of transition out of marriage on physical and mental health, as well as the reported HRQoL outcomes in future explorations among Polish females and males, while also contributing to current research concerning this subject.

\section{Conclusion}

In sum, it appears that our results are more consistent with the social causation paradigm. In terms of mental health, especially the existence of depression, the social causation paradigm seemed to be useful because transition out of marriage/cohabitation was strongly connected with the higher rates of depression occurrence. This particularly refers to men and women transitioned to a divorced life, as well as widowed men because the odds of getting depression among these groups were much higher compared to their continuously married counterparts. However, the lack of significant change in the case of disability assessment among those transitioned to a divorce/separation, as well as to widowhood 
compared to continuously married contrasts with the social causation model. In the case of HRQoL, the social causation paradigm could especially explain significantly lower rate after marital transition among widowed males compared to their continuously married counterparts. Nevertheless, significant change in the HRQoL rate has not been observed statistically between the 1st and 2nd wave of the survey among both men and women transitioned to a widowed and a divorced life.

Acknowledgements The research leading to these results has received funding from the European Community's Seventh Framework Programme (FP7/2007-2013) under grant agreement number 223071 (COURAGE in Europe), Polish Ministry for Science and Higher Education grant for an international cofinanced project (1277/7PR/ UE/2009/7, 2009-2012) and Jagiellonian University Medical College grant for project COURAGE-POLFUS (K/ZDS/005241).

\section{Compliance with Ethical Standards}

Conflict of Interest No conflict of interest.

Open Access This article is distributed under the terms of the Creative Commons Attribution 4.0 International License (http://creativecommons.org/licenses/by/4.0/), which permits unrestricted use, distribution, and reproduction in any medium, provided you give appropriate credit to the original author(s) and the source, provide a link to the Creative Commons license, and indicate if changes were made.

\section{References}

Allison, P. D. (1999). Comparing logit and Probit coefficients across groups. Sociological Methods \& Research, 28(2), 186-208.

Amato, P. R. (2010). Divorce in Europe and the United States: Commonalities and differences across nations. Family Science, 1(1), 2-13.

Amato, P. R. (2010a). Research on divorce: Continuing trends and new developments. Journal of Marriage and Family, 72(3), 650-666.

American Psychiatric Association. (1994). Diagnostic and statistical manual of mental disorders (4th ed.). Washington DC: American Psychiatric Association.

Antonucci, T. C., \& Akiyama, H. (1987). An examination of sex differences in social support among older men and women. Sex Roles, 17(11-12), 737-749.

Argyle, M. (1999). Causes and correlates of happiness. In D. Kahneman, E. Diener, \& N. Schwarz (Eds.), Well-being: The foundations of hedonic psychology (pp. 353-373). New York: Russell Sage Foundation.

Barrett, A. E. (2000). Marital trajectories and mental health. Journal of Health and Social Behavior, 41(4), 451-464.

Bennett, M. K. (2006). Does marital status and marital status change predict physical health in older adults? Psychological Medicine, 36(9), 1313-1320.

Birch, A. (1997). Developmental Psychology. From infancy to adulthood (Second ed.). London: Macmillan Press LTD.

Blekesaune, M. (2008). Partnership transitions and mental distress: Investigating temporal order. Journal of Marriage and Family, 70, 879-890.

Booth, A., \& Amato, P. R. (1991). Divorce and psychological stress. Journal of Health and Social Behavior, 32(4), 396-407.

Bowling, A. (1997). Measuring Health: A Review of Quality of Life Measurements Scales. Buckingham, Philadelphia: Open University Press.

Bowling, A. (2001). Measuring Disease. A Review of Disease-Specific Quality of Life Measurements Scales. Second Edition. Buckingham, Philadelphia: Open University Press. 
Bruce, L. M., \& Kim, K. (1992). Differences in the effects of divorce on major depression in men and women. American Journal of Psychiatry, 149(7), 914-917.

Caballero, F. F., Miret, M., Power, M., Chatterji, S., Tobiasz-Adamczyk, B., Koskinen, S., \& Ayuso-Mateos, J. L. (2013). Validation of an instrument to evaluate quality of life in the aging population: WHOQOLAGE. Health and Quality of Life Outcomes, 11, 177.

Carr, D. (2004). Gender, pre-loss marital dependence, and older adults' adjustment to widowhood. Journal of Marriage and Family, 66(1), 220-235.

Carr, D., \& Springer, K. W. (2010). Advances in families and health research in the 21 st century. Journal of Marriage and Family, 72(3), 743-761.

Carstensen, L. (1992). Social and emotional patterns in adulthood: Support for socio-emotional selectivity theory. Psychology and Aging, 7(3), 331-338.

Central Statistical Office. (2017). Demographic Yearbook of Poland 2017. Statistical PublishingEstablishment.File:/// C:/users/wojcikg/AppData/local/temp/demographic_yearbook_of_Poland_2017.Pdf. Accessed: 27.04.2018.

Chappell, N. L. (1989). Health and helping among the elderly. Journal of Aging and Health, 1(1), 102-120.

Chen, J. H., Bierhals, A. J., Prigerson, H. G., Kasl, S. V., Mazure, C. M., \& Jacobs, S. (1999). Gender differences in the effects of bereavement related psychological distress in health outcomes. Psychological Medicine, 29(2), 367-380.

Chipperfield, J., \& Havens, B. (2001). Gender differences in the relationship between marital status transitions and life satisfaction in later life. Journals of Gerontology Series B-Psychological Sciences and Social Sciences, 56(3), 176-186.

Dalgard, O. S. (1996). Community health profile: A tool for psychiatric prevention. In D. R. Trent \& C. A. Reed (Eds.), Promotion of mental health (pp. 681-695). Aldershot: Avebury Press.

Dupre, E. M., \& Meadows, O. S. (2007). Disaggregating the effects of marital trajectories on health. Journal of Family Issues, 28(5), 623-652.

Ensel, W. M., Kristen, P. M., Lin, N., \& Lai, G. (1996). Stress in the life course: A life history approach. Journal of Aging and Health, 8(3), 389-416.

Gardner, J., \& Oswald, A. J. (2006). Do divorcing couples become happier by breaking up. Journal of the Royal Statistical Society Series A - Statistics in Society, 169(2), 319-336.

Gustavson, K., Røysamb, E., von Soest, T., Johansson Helland, M., \& Schjelderup Mathiesen, K. (2012). Longitudinal associations between relationship problems, divorce, and life satisfaction: Findings from a 15-year population-based study. The Journal of Positive Psychology, 7(3), 188-197.

Haro, J. M., Arbabzadeh-Bouchez, S., Brugha, T. S., Girolamo De, G., Guyer, M. E., Jin, R., Lepine, J. P., Mazzi, F., Reneses, B., Vilagut, G., Sampson, N. A., \& Kessler, R. C. (2006). Concordance of the composite international diagnostic interview version 3.0 (CIDI 3.0) with standardized clinical assessments in the WHO world mental health surveys. International Journal of Methods in Psychiatric Research, 15(4), 167-180.

Holmes, T. H., \& Rahe, R. H. (1967). The social readjustment rating scale. Journal of Psychosomatic Research, 11, 213-225.

Hope, S., Rodgers, B., \& Power, C. (1999). Marital status transitions and psychological distress: Longitudinal evidence from a national population sample. Psychological Medicine, 29(2), 381-389.

Horwitz, A. V., White, H. R., \& Howell-White, S. (1996). The use of multiple outcomes in stress research: A case study of gender differences in responses to marital dissolution. Journal of Health and Social Behavior, 17, 278-291.

Johnson, D. R., \& Wu, J. (2002). An empirical test of crisis, social selection and role explanations of the relationship between marital disruption and psychological distress: A pooled time-series analysis of fourwave panel data. Journal of Marriage and Family, 64(1), 211-224.

Kamp Dush, C. M., \& Amato, P. R. (2005). Consequences of relationship status and quality for subjective well-being. Journal of Social and Personal Relationships, 22(5), 607-627.

Kasearu, K., \& Kutsar, D. (2011). Patterns behind unmarried cohabitation trends in Europe. European Societies, 13(2), 307-325.

Kim, H. K., \& McKenry, M. (2002). The relationship between marriage and psychological well-being. Journal of Family Issues, 23(8), 885-911.

Lamb, K., Lee, G. R., \& De Maris, A. (2003). Union formation and depression: Selection and relationship effects. Journal of Marriage and Family, 65(4), 953-962.

Lee, G. R., \& DeMaris, A. (2007). Widowhood, gender and depression. A longitudinal analysis. Research on Aging, 29(1), 56-72.

Leonardi, M., Chatterrji, S., Koskinen, S., Ayuso-Mateos, J. L., Haro, J. M., Frisoni, G., Frattura, L., Martinuzzi, L., Tobiasz-Adamczyk, B., Gmurek, M., Serrano, R., \& Finocchiaro, C. (2014). 
Determinants of health and disability in ageing population: The COURAGE in Europe project (collaborative research on ageing in Europe). Clinical Psychology \& Psychotherapy, 21(3), 193-198.

Lucas, R. E. (2005). Time does not heal all wounds: A longitudinal study of reaction and adaptation to divorce. Psychological Science, 16(12), 945-950.

Lucas, R. E. (2008). Personality and subjective well-being. In M. Eid \& R. J. Larsen (Eds.), The science of subjective well-being (pp. 171-194). New York: The Guilford Press.

Marks, N. F., Lambert, J. D. (1996). Marital status continuity and change among young and midlife adults: Longitudinal effects on psychological well-being, National Survey of Families and Households. NSFH Working Paper, 71.

Mastekaasa, A. (1994). Psychological well-being and marital dissolution: Selection effects. Journal of Family Issues, 15, 208-228.

Medvedev, O. N., \& Landhuis, C. E. (2018). Exploring constructs of well-being, happiness and quality of life. PeerJ,6, https://www.ncbi.nlm.nih.gov/pmc/articles/PMC5985772/. Accessed: 7.11.2018.

Miller, N. B., Smerglia, V. L., Gaudet, D. S., \& Kitson, G. C. (1998). Stressful life events, social support, and the distress of widowed and divorced women. A counteractive model. Journal of Family Issues, 19(2), 181-203.

Miret, M., Caballero, F. F., Chatterji, S., Olaya, B., Tobiasz-Adamczyk, B., Koskinen, S., Leonardi, M., Haro, J. M., \& Ayuso-Mateos, J. L. (2014). Health and happiness: Cross-sectional household surveys in Finland, Poland and Spain. Bulletin of the World Health Organization, 92(10), 716-725.

Moussavi, S., Chatterji, S., Verdes, E., Tandon, A., Patel, V., \& Ustun, B. (2007). Depression, chronic diseases, and decrements in health: Results from the world health surveys. The Lancet, 370(9590), 851-858. https://doi.org/10.1016/S0140-6736(07)61415-9 Accessed: 4.04.2018.

Musick, K., \& Bumpass, L. (2010). Re-examining the case for marriage: Variation and change in well-being and relationships. California Center for Population Research: On-line Working Paper Series. http://papers. ccpr.ucla.edu/papers/PWP-CCPR-2006-003/PWP-CCPR-2006-003.pdf/. Accessed: 2.11.2018.

Næss, S., Blekesaune, M., \& Jakobsson, N. (2015). Marital transitions and life satisfaction: Evidence from longitudinal data from Norway. Acta Sociologica, 58(1), 63-78.

Pearlin, L. (1989). The sociological study of stress. Journal of Health and Social Behavior, 30, 241-256.

Perelli-Harris, B., Mynarska, M., Berrington, A., Berghammer, C., Evans, A., Isupova, O., Keizer, R., Klärner Lappegård, T., \& Vignoli, D. (2014). Towards a new understanding of cohabitation: Insights from focus group research across Europe and Australia. Demographic Research, 31(34), 1043-1078.

Pevalin, D. J., \& Ermisch, J. (2004). Cohabiting unions, repartnering and mental health. Psychological Medicine, 34, 1553-1559.

Pienta, A. M., Hayward, M. D., \& Jenkins, K. R. (2000). Health consequences of marriage and retirement years. Journal of Family Issues, 21(5), 559-586.

Power, M., Quinn, K., \& Schmidt, S. (2005). Development of the WHOQOL-old module. Quality of Life Research, 14(10), 2197-2214.

Raciborski, Ł. (2012). Health status [Stan zdrowia]. In A. Giza \& M. Sikorska (Eds.), Contemporary Polish Society [Współczesne społeczeństwo polskie] (pp. 103-138). Warszawa: PWN.

Raggi, A., Corso, B., Minicuci, N., Quintas, R., Sattin, D., De Torres, L., Chatterji, S., Griboni, G. B., Haro, J. M., Koskinen, S., Martinuzzi, A., Miret, M., Tobiasz-Adamczyk, B., \& Leonardi, M. (2016). Determinants of quality of life in ageing populations: Results from a cross-sectional study in Finland, Poland and Spain. PLoS One, 11(7), e0159293.

Rogers, R. G. (1995). Marriage, sex, and mortality. Journal of Marriage and Family, 57(2), 515-526.

Ross, C. E. (1995). Reconceptualizing marital status as a continuum of social attachment. Journal of Marriage and Family, 57, 129-140.

Rydzewski, P. (2010). Sociological analyses of divorce. Theoretical, empirical and methodological aspects. In Socjologiczne analizy rozwodów. Aspekty teoretyczne, empiryczne i metodologiczne. Lublin: Wydawnictwo WSPA.

Schoen, R., Landale, N. S., \& Daniels, K. (2007). Family transitions in young adulthood. Demography, 44(4), 807-820.

Simon, R. (2002). Revisiting the relationships among gender, marital status and mental health. American Journal of Sociology, 107(4), 1065-1096.

Soons, J. P. M., \& Kalmijn, M. (2009). Is marriage more than cohabitation? Well-being differences in 30 European countries. Journal of Marriage and Family, 71(5), 1141-1157.

Soons, J. P. M., Liefbroer, A. C., \& Kalmijn, M. (2009). The long-term consequences of relationship formation for subjective well-being. Journal of Marriage and Family, 71(5), 1254-1270.

Stroebe, M., Stroebe, W., \& Schut, H. (2001). Gender differences in adjustment to bereavement: An empirical and theoretical review. Review of General Psychology, 5, 62-83. 
Strohschein, L., McDonough, P., Monette, G., \& Shao, Q. (2005). Marital transitions and mental health: Are there gender differences in the short-term effects of marital status change. Social Science \&Medicine, 61(11), 2293-2303.

Szukalski, P. (2007). Differentiation of mortality rate and marital status [Zróżnicowanie poziomu umieralności a stan cywilny]. Wiadomości Statystyczne, 5, 33-43.

Szukalski, P. (2013). Marriage. Beginning and the End [Malżeństwo. Początek i koniec]. Łódź: Wydawnictwa Uniwersytetu Łódzkiego.

Taylor, S. E., Klein, L. C., Lewis, B. P., Gruenewald, T. L., Gurung, R. A., \& Updegraff, J. A. (2000). Biobehavioral responses to stress in females: Tend-and-befriend, not fight-or-flight. Psychological Review, 107(3), 411-429.

The WHOQOL Group. (1995). The World Health Organization quality of life assessment (WHOQOL): Position paper from the World Health Organization. Social Science \& Medicine, 41(10), 1403-1409.

The WHOQOL Group. (1998). Development of the World Health Organization WHOQOL-BREF quality of life assessment. Psychological Medicine, 28(3), 551-558.

Tobiasz-Adamczyk, B. (2013). The genesis of health: Evolution of the concept of health-related quality of life. In K. Kawecka-Jaszcz, M. Klocek, B. Tobiasz-Adamczyk, \& C. J. Bulpitt (Eds.), Health-related quality of life in cardiovascular patients (pp. 1-8). New York: Springer.

Tobiasz-Adamczyk, B. (2009). Socio-cultural determinants of women's health in middle age [Uwarunkowania społeczno-kulturowe zdrowia kobiet w średnim wieku]. Problemy Higieny $i$ Epidemiologii, 90(4), 441-446.

Turner, R. J. (2003). The pursuit of socially modifiable contingencies in mental health. Journal of Health and Social Behavior, 44(1), 17.

Umberson, D. (1992). Gender, marital status and the social control of health behavior. Social Science \& Medicine, 34(8), 907-917.

Umberson, D., Wortman, C. B., \& Kessler, R. C. (1992). Widowhood and depression: Explaining long-term gender differences in vulnerability. Journal of Health and Social Behavior, 33(1), 10-24.

Umberson, D., Liu, H., Powers, D. (2009) Marital Status, Marital Transitions, and Body Weight. Journal of Health and Social Behavior 50(3):327-343

Umberson, D., Thomeer, M. B. \& Williams. K. (2013). Family Status and Mental Health: Recent Advances and Future Directions. In C. S. Aneshensel,J. C. Phelan, A. Bierman (Eds.) Handbook of the Sociology of Mental Health. Second Edition.Springer: Dordrecht Heidelberg New York London.

Üstün, B., Kostanjsek, N., Chatterji, S., \& Rehm, J. (2010). Measuring health and disability - Manual for WHO disability assessment schedule WHODAS 2.0. Geneva: World Health Organization.

Wade, T., \& Pevalin, J. D. (2004). Marital transitions and mental health. Journal of Health and Social Behavior, 45(2), 155-170.

Wilcox, S., Aragaki, A., Mouton, P. C., Evenson, K., Wassertheil-Smoller, S., \& Loevinger, B. (2003). The effects of widowhood on physical and mental health, health behaviors, and health outcomes: The Women's health Inititative. Health Psychology, 22(5), 513-522.

Williams, K. (2003). Has the future of marriage arrived? A contemporary examination of gender, marriage and psychological well-being. Journal of Health and Social Behavior, 44(4), 470-487.

Williams, K., \& Umberson, D. (2004). Marital status, marital transitions, and health: A gendered life course perspective. Journal of Health and Social Behavior, 45(1), 81-98.

Williams, K., French, A., \& Carlson, D. L. (2010). Marital Status and Mental Health. In T. L. Scheid \& T. N. Brown (Eds.), A handbook for the study of mental health (pp. 306-320). Cambridge: Cambridge University Press.

World Health Organization. WHO Disability Assessment Schedule 2.0 (WHODAS 2.0). http://www.who. int/classifications/icf/more_whodas/en/. Accessed: 8.11.2018.

Wu, Z., \& Hart, R. (2002). The effects of marital and non-marital union transition on health. Journal of Marriage and Family, 64(2), 420-432.

Wu, Z., Schimmele, C. M., Penning, M. J., Zheng, C., \& Noh, S. (2012). Effect of marital status on duration of treatment for mental illness. Canadian Studies in Population, 39(1-2), 109-124.

Zawisza, K., Galas, A., Tobiasz-Adamczyk, B., Chatterji, S., Haro, J. M., Miret, M., Koskinen, S., Power, M., \& Leonardi, M. (2014). The validity of the instrument to evaluate social network in the ageing population: The collaborative research on ageing in Europe social network index. Clinical Psychology \& Psychotherapy, 21(3), 227-241.

Zawisza, K., Gałaś, A., \& Tobiasz-Adamczyk, B. (2015). Polish version of the courage social network index — The scale for the assessment of social networks [Polska wersja courage social network index — Skali do oceny poziomu sieci społecznych]. Gerontologia Polska, 22(2), 31-41. 
Zawisza, K., Gałaś, A., \& Tobiasz-Adamczyk, B. (2016). Validation of the polish version of the WHOQOLAGE scale in older population [Walidacja polskiej wersji skali oceny jakości życia WHOQOL-AGE w populacji osób starszych]. Gerontologia Polska, 24(1), 7-16.

Zella, S. (2017). Marital status transitions and self-reported health among Canadians: A life course perspective. Applied Research in Quality of Life, 12(2), 303-325.

Zisook, S., \& Shuchter, S. R. (1991). Early psychological reaction to the stress of widowhood. Psychiatry, 54(4), 320-333.

Publisher's Note Springer Nature remains neutral with regard to jurisdictional claims in published maps and institutional affiliations.

\section{Affiliations}

\section{Grzegorz Wójcik $^{1} \cdot$ Katarzyna Zawisza $^{1} \cdot$ Katarzyna Jabłońska $^{1} \cdot$ Tomasz $^{2}$ Grodzicki $^{2} \cdot$ Beata Tobiasz-Adamczyk $^{1}$}

1 Department of Medical Sociology, Chair of Epidemiology and Preventive Medicine, Jagiellonian University Medical College, Kopernika 7a, 31-034, Krakow, Poland

2 Chair of Internal Medicine and Gerontology, Jagiellonian University Medical College, Śniadeckich 10, 31-531, Krakow, Poland 